\title{
The Neural Circuitry of Executive Functions in Healthy Subjects and Parkinson's Disease
}

\author{
Sandra E Leh ${ }^{1}$, Michael Petrides ${ }^{2}$ and Antonio P Strafella*,1,3,4 \\ ${ }^{1}$ Division of Brain Imaging and Behaviour - Systems Neuroscience, Toronto Western Research Institute (TWRI), UHN, \\ University of Toronto, Toronto, ON, Canada; ${ }^{2}$ Montreal Neurological Institute and Hospital, McGill University, Montreal, \\ Canada; ${ }^{3}$ Division of Neurology, Toronto Western Hospital, UHN, University of Toronto, Toronto, ON, Canada; ${ }^{4}$ PET Imaging \\ Centre, Centre for Addiction and Mental Health (CAMH), University of Toronto, Toronto, ON, Canada
}

In our constantly changing environment, we are frequently faced with altered circumstances requiring generation and monitoring of appropriate strategies, when novel plans of action must be formulated and conducted. The abilities that we call upon to respond accurately to novel situations are referred to as 'executive functions', and are frequently engaged to deal with conditions in which routine activation of behavior would not be sufficient for optimal performance. Here, we summarize important findings that may help us understand executive functions and their underlying neuronal correlates. We focus particularly on observations from imaging technology, such as functional magnetic resonance imaging, position emission tomography, diffusion tensor imaging, and transcranial magnetic stimulation, which in the past few years have provided the bulk of information on the neurobiological underpinnings of the executive functions. Further, emphasis will be placed on recent insights from Parkinson's disease (PD), in which the underlying dopaminergic abnormalities have provided new exciting information into basic molecular mechanisms of executive dysfunction, and which may help to disentangle the cortical/subcortical networks involved in executive processes.

Neuropsychopharmacology Reviews (2010) 35, 70-85; doi:I0.1038/npp.2009.88; published online 5 August 2009

Keywords: executive functions; Parkinson's disease; PET; fMRI; neuroimaging; dopamine

\section{INTRODUCTION}

On a daily basis, we are constantly faced with changing circumstances that require planning and generation of novel actions. The abilities that we call upon to respond accurately to new situations are often referred to as 'executive functions', and are frequently used for managing conditions in which routine activation of behavior would not be sufficient for optimal performance, and in which topdown control is required to modify behavior. Executive processes are those cognitive mechanisms by which performance is optimized in situations requiring the simultaneous operation of a number of different processes (Baddeley, 1986). They are regularly called upon when sequences of responses must be generated and scheduled, and when novel plans of action must be formulated and conducted (Owen, 2004).

${ }^{*}$ Correspondence: Dr AP Strafella, Division of Neurology, CAMH-PET imaging center, Toronto Western Hospital/Research Institute, University of Toronto, Toronto, ON, Canada M5T2S8, Tel: +416 603 5706,

Fax: + 4166035004

E-mail: antonio.strafella@uhnres.utoronto.ca or antonio.strafella@camhpet.ca Received 2 May 2009; revised 1 July 2009; accepted 1 July 2009
Several aspects of executive function have been described, including, among others, planning and initiating sequences of responses, cognitive flexibility, abstract thinking, rulebased regulation of behavior, inhibiting inappropriate actions, and selecting relevant sensory information. Traditionally, the frontal cortex has been considered the major brain structure involved in executive functions (Luria, 1971; Shallice, 1982; Dubois et al, 1995). More recently, however, several studies in subjects with frontal lesions have shown a large variety of behavioral disturbances other than executive dysfunctions that include, for example, apathy, poor motivation, irritability, euphoric state, etc (Andrés, 2003; Godefroy, 2003), highlighting the importance of not using the term executive functions interchangeably with frontal functions.

As we have noted above, executive functions are widely associated with the frontal cortex, in particular, with the dorsolateral prefrontal cortex (DLPFC), which is involved in certain aspects of working memory (Petrides, 2000) and cognitive flexibility (Milner, 1963; Goldman-Rakic, 1987), and with the ventrolateral and orbital prefrontal cortex (PFC), which is involved in emotional processing, acquisition, and reversal of stimulus-reward associations (Nauta, 1971; Rolls, 2000) (Figure 1). 
Patients with lateral frontal dysfunction may exhibit impaired mental flexibility, and difficulty in maintaining and re-directing their attention. On neuropsychological testing, impaired cognitive set shifting (flexibility) is often shown on the Wisconsin Card Sorting Test (WCST) (Milner, 1963) and various Go/No-go tests (Tekin and Cummings, 2002). In contrast, dysfunctions of the orbitofrontal circuit often lead to personality changes, behavioral disinhibition, emotional lability, and impaired reward processing (Eslinger and Damasio, 1985), and these patients very often perform normally on the WCST (Tekin and Cummings, 2002). More recently, it has been recognized that executive functions not only depend on frontal-cortical areas but also on several other brain areas that are closely linked with the frontal cortex and form larger executive neural networks (for example, see Andrés, 2003; Owen, 2004; Collette et al, 2006; Champod and Petrides, 2007). For instance, the frontal cortex is strongly linked with the limbic region of the medial temporal lobe, which includes the hippocampus, the amygdala, and the entorhinal/parahippocampal cortex, and these connections are critical for mnemonic interactions and the regulation of emotional responses (for example, see Petrides, 1996, 2007; Barbas, 2007; Bast, 2007). The PFC and the hippocampus both innervate the nucleus accumbens, which is essential for integrating cortical and limbic information into goal-directed behavior (Pennartz et al, 1994). Furthermore, it is connected with the globus pallidum, the substantia nigra, and the hypothalamus. A study in Parkinson's disease (PD) patients and age-matched controls using $\mathrm{H}_{2}^{15} \mathrm{O}$-PET (position emission tomography) and the Tower of London (TOL) (Dagher et al, 2001), a task that requires advance planning of action, documented that PD patients performed as well as the control group, but showed a different pattern of neuronal activation. PD patients did not show activity in the right caudate nucleus during the TOL task, but showed task-related $\mathrm{rCBF}$ increases in the right hippocampus. This recruitment
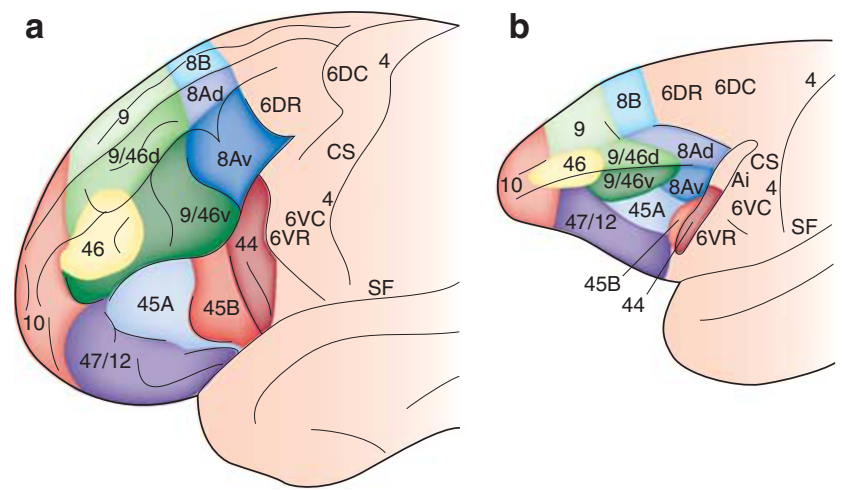

Figure 1. Cytoarchitectonic map of the lateral surface of the prefrontal cortex of (a) the human brain and (b) the macaque monkey brain by Petrides and Pandya (1994). Ai, inferior arcuate sulcus; CS, central sulcus; SF, Sylvian fissure. (Adapted and reproduced with permission from Petrides and Pandya, 1994). of the hippocampus has been interpreted as a mechanism to overcome the striatal defect, possibly resulting from insufficient working memory capacity within the frontostriatal system. The frontostriatal system is involved in cognitive tasks, such as planning, skill learning, set shifting, and habit learning. All these tasks involve the gradual learning of responses through trial and error. The hippocampal system mediates a different, more rapid, and flexible type of learning. Experimental evidence suggests that the two systems may work independently, act together, or interfere with one another in different situations. In particular, when the short-term memory capacity of the frontostriatal system is exceeded, the hippocampal system may be recruited (Dagher et al, 2001).

There is also evidence of a frontoparietal network involved in executive functions, directing attention to space and memory (Baddeley, 1998; Diwadkar, Carpenter and Just, 2000; Petrides and Pandya, 2002; Sauseng et al, 2002). Both the mid-DLPFC region (area 9/46) and the posterior lateral frontal region (areas $8 \mathrm{~A}$ and $8 \mathrm{~B}$ ), including the premotor rostral area 6 , are connected with posterior parietal areas (Petrides and Pandya, 2002). The involvement of the parietal cortex in working memory processes is further supported by lesion (Carlesimo et al, 2001) and transcranial magnetic stimulation (TMS) studies (Oliveri et al, 2001), but its role has remained unclear. Recently, Champod and Petrides (2007) have provided evidence that cortex within the intraparietal sulcus has a role in the manipulation of information in working memory, whereas the monitoring of that information during working memory processes has been associated with the mid-DLPFC (Petrides, 1991, 1995, 2000). The linkage of a part of the posterior parietal cortex in the mental manipulation of information in memory (Champod and Petrides, 2007) extends into the field of working memory, the well-known critical interaction between parietal cortex and frontal cortex in reaching stimuli in space, in orienting attention to stimuli, and mentally manipulating them in space (for example, see Burnod et al, 1999; Petrides and Pandya, 2002).

Studies in rodents and non-human primates have shown regulation by the PFC of emotional/motivational processes linked to the amygdala (Rosenkranz and Grace, 1999; Maskati and Zbrozyna, 1989; Dias et al, 1996). In humans, functional magnetic resonance imaging (fMRI) studies and ${ }^{18}$ fluorodeoxyglucose (FDG)-PET studies have provided evidence of a link between the amygdala and PFC (for example, see Pezawas et al, 2005; Hariri et al, 2000, 2003). The amygdala has particularly strong connections with the caudal and medial orbitofrontal areas, and these connections seem to be involved in modifying endocrine, autonomic, and involuntary behavioral responses, as well as emotional processing such as screening and assessing emotional aspects of the environment for further decisions and actions (Tekin and Cummings, 2002; Petrides, 2007; Barbas, 2007). 


\section{NEUROANATOMY AND NEUROIMAGING STUDIES OF EXECUTIVE FUNCTIONS}

There is cumulative evidence that subcortical lesions affecting cortical input to the striatum may compromise executive functions (Godefroy, 2003). The striatum is the main entry point of cortical information to the basal ganglia, and receives afferents from anatomically and functionally different areas of the cerebral cortex. According to the current model of basal ganglia function, cortical information is processed in the basal ganglia nuclei and information is sent back to the cortex through the thalamus ('cortico-basal ganglia loop') (Alexander and Crutcher, 1990; Alexander et al, 1986). Experimental anatomical tracing studies in monkeys have identified three parallel loops of corticostriatal connections: (1) The limbic loop, which is involved in emotional/motivational and stereotyped behavior, and has been implicated in attention deficit disorder, hyperactivity disorder, compulsive disorders, and Tourette's syndrome (Grabli et al, 2004), includes the ventromedial striatum, nucleus accumbens, rostral/ventral caudate nucleus, and putamen, which receive input from orbital and medial PFC (Haber et al, 1995); (2) the associative loop, implicated in cognitive functions, such as attention, controlled retrieval, and monitoring of information within working memory (Kostopoulos and Petrides, 2003; Levy and Goldman-Rakic, 2000; Petrides, 2002, 2005; Petrides and Pandya, 2002; Grabli et al, 2004; Rizzuto et al, 2005), involving the head of the caudate and areas of the rostral putamen, which receive input from the lateral PFC, pre-supplementary motor area (SMA), and posterior parietal cortex (Haber et al, 2006; Calzavara et al, 2007; Parent, 1990; Parent and Hazrati, 1995); and (3) the sensorimotor loop, implicated in motor functions (Grabli et al, 2004), involving caudal and lateral aspects of the putamen, which receive input from the somatosensory, primary, and SMAs (Alexander and Crutcher, 1990). The PFC has significant connections with the head of the caudate nucleus, which are topographically organized (see Figure 2). The medial and dorsal prefrontal areas project

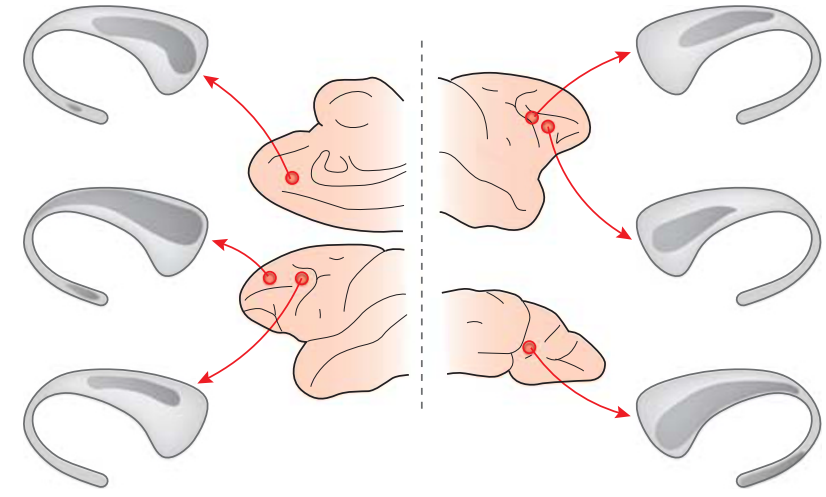

Figure 2. Summary diagrams showing the connectional relationships between the dorsal and the ventral architectonic trends of the prefrontal cortex and the caudate nucleus in the sagittal plane (adapted and reproduced with permission from Yeterian and Pandya, 1991). predominantly to the dorsal and central area within the head of the caudate nucleus, whereas orbital and inferior prefrontal areas project mainly to the ventromedial and central caudate nucleus (Selemon and Goldman-Rakic, 1985; Yeterian and Pandya, 1991). A small number of axonal fibers has also been described to project to the putamen and the tail of the caudate nucleus.

\section{Diffusion Tensor Imaging (DTI) Studies}

At present, knowledge of the functional organization of corticostriatal networks originates largely from animal experiments (Nakano et al, 2000; Nambu et al, 2002; Selemon and Goldman-Rakic, 1985; Takada et al, 1998). However, recent advances in neuroimaging methods, such as DTI, are providing us with new approaches for investigating cortical connectivity in humans in vivo. Using this technique, a recent study provided evidence in the human brain for several corticostriatal pathways between the frontal cortex and the caudate nucleus and putamen (Leh et al, 2007). This study showed that, although the human caudate nucleus is interconnected with the PFC, inferior and middle temporal gyrus, frontal eye fields, cerebellum, and thalamus, the putamen was interconnected with the PFC, primary motor area, primary somatosensory cortex, SMA, premotor cortex, cerebellum, and thalamus (Figure 3). In addition, a connectivity-based seed classification analysis identified connections between the DLPFC and the dorsal-posterior caudate nucleus, and between the ventro-lateral prefrontal cortex (VLPFC) and the ventralanterior caudate nucleus. For the putamen, connections existed between the SMA and dorsal-posterior putamen, while the premotor area projected to medial putamen, and the primary motor area to the lateral putamen.

The above DTI study (Leh et al, 2007) showed several striatal pathways in humans, and provided evidence of an anatomical organization between frontal cortex and the caudate nucleus and putamen. More specifically, while the DLPFC was strongly linked to the dorsal-posterior caudate ('associative loop'), the VLPFC was mainly interconnected with the ventral caudate ('limbic loop'). These results are in keeping with earlier anatomical reports by Yeterian and Pandya (1991), suggesting that prefrontal connections are organized topographically. The confirmation of dorsolateral prefrontal connections to the dorsal-posterior caudate is also consistent with previous functional imaging studies proposing the existence of a 'dorsolateral prefrontal loop' (Jueptner and Weiller, 1998). With regard to the connection between VLPFC and ventral caudate nucleus, corroboration can be found from functional MRI studies during setshifting tasks (Monchi et al, 2006b; Nakano et al, 2000), as well as from anatomical studies in monkeys (Selemon and Goldman-Rakic, 1985; Yeterian and Pandya, 1991). This organization along a dorsal-ventral axis may be explained by the different functional contributions of these two loops. Several studies have shown that, whereas the DLPFC seems to have a part in divided attention and monitoring of 
a
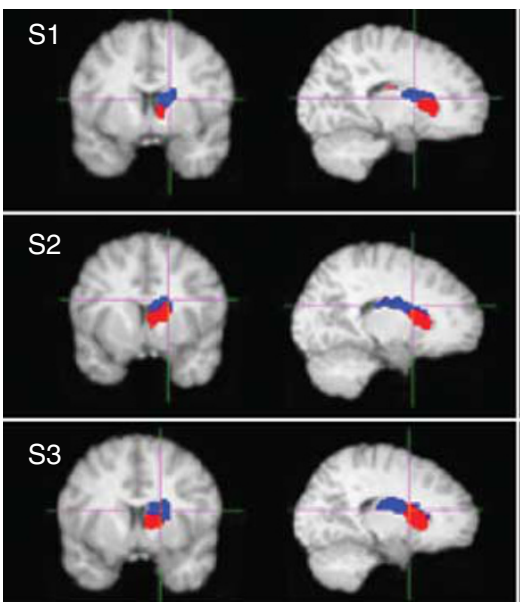

DLPFC

VLPFC
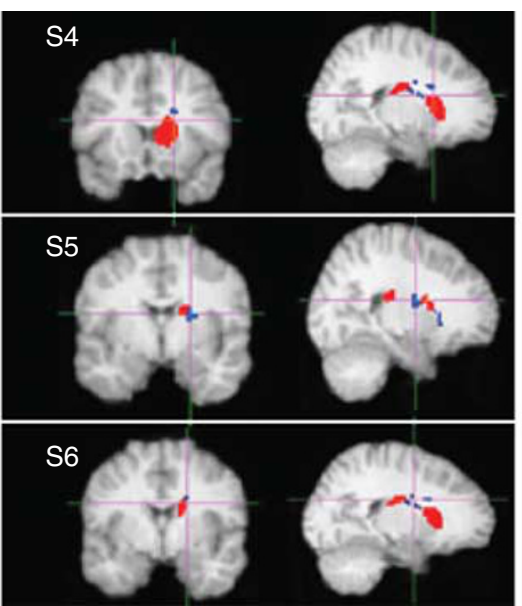

b

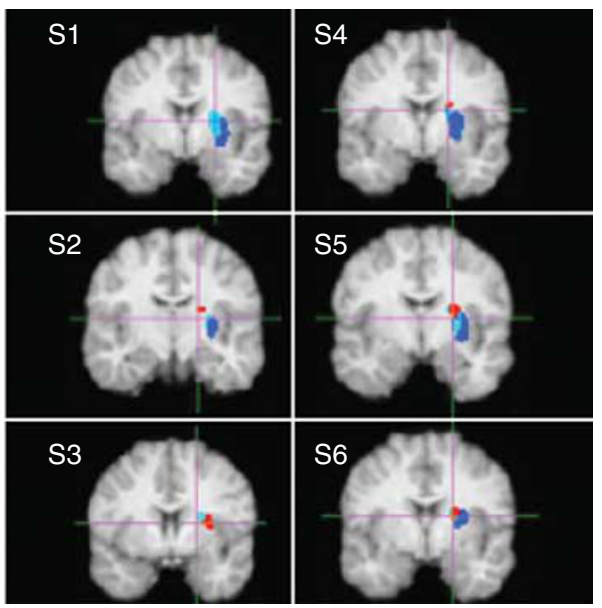

$\square$ Premotor $\square$ Primary motor $\square$ SMA

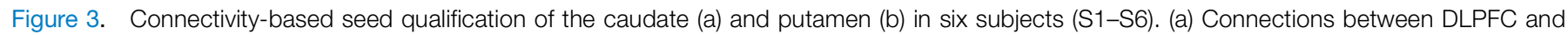

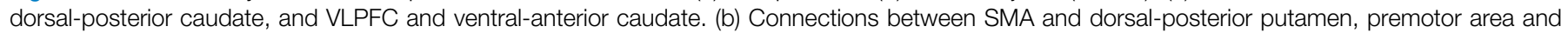
medial putamen, and primary motor area and lateral putamen. (Adapted and reproduced with permission from Leh et al, 2007).

information within working memory (Kostopoulos and Petrides, 2003; Petrides, 2005; Rizzuto et al, 2005), the VLPFC seems to have a specific role in memory retrieval (Kostopoulos and Petrides, 2003; Petrides, 2005).

Lehericy et al (2004) showed similar connections from the head of the caudate to the frontal pole, the pre-SMA, the medial, ventral, and dorsolateral PFC. Similar connections were found from the rostral putamen. The posterior putamen showed connections to the primary sensory/motor area and the posterior SMA, whereas the ventral striatum revealed connections to the orbitomedial frontal cortex, amygdala, hippocampus, and temporal lobe. These prefrontal-striatal connections may constitute the anatomical substrate underlying executive dysfunctions as well as the visuospatial disorientation associated with neurological (for example, PD) and psychiatric (for example, schizophrenia) conditions (Monchi et al, 2004; Park and Holzman, 1993; Parnetti and Calabresi, 2006; Prasad et al, 2005; RodriguezSanchez et al, 2005). For instance, Matsui et al (2007) showed a significant reduction of the fractional anisotropy in the left parietal white matter in non-demented PD patients who performed poorly on the WCST.

\section{fMRI Studies}

Executive functions rely on interactions between many brain areas. Neuroimaging studies have shown increased activity in brain areas other than the PFC that have traditionally been linked to executive functions. Some of these studies using the WCST, for example, have shown activation in lateral prefrontal, parietal, temporal, and hippocampal cortex, as well as in the basal ganglia (Rezai et al, 1993; Berman et al, 1995; Nagahama et al, 1995; Barceló et al, 1997; Barceló and Rubia, 1998; Konishi et al, 1998; Mentzel et al, 1998; Ragland et al, 1998). In other neuroimaging studies using the Stroop test, orbitofrontal, parietal, temporal, left inferior frontal, as well as anterior cingulate gyrus seemed to be involved (Bench et al, 1993; Larrue et al, 1994; Pardo et al, 1990).

Furthermore, Konishi and colleagues (1998) were able to document how human cerebral hemispheres, during executive tasks, are asymmetrically specialized. In their eventrelated functional MRI study, set-shifting paradigms derived from the WCST were used, in which the subjects update behavior on the basis of environmental feedback. The cognitive requirements constituting the paradigms were decomposed into two components according to temporal stages of task events. Double dissociation of the component brain activity was found, bilaterally, in three regions in the lateral frontal cortex; the right regions being activated during exposure to negative feedback and the corresponding left regions being activated during updating of behavior, suggesting that both hemispheres contribute to cognitive set shifting, but in different ways. The asymmetrical hemispheric specialization within the same paradigms further implied an interhemispheric interaction of these task components that achieve a common goal.

Hemispheric lateralization within the PFC is an important aspect of executive function (Aron et al, 2004a, b; Johnson et al, 2003; Tulving et al, 1994), and there is some evidence that the left frontal lobe may be involved in task-setting, while the right frontal lobe may be more involved with monitoring (Stuss and Alexander, 2007). Several neuroimaging studies support this task-specific lateralization of the PFC in humans. During the performance of the WCST, left DLPFC activation has been reported when a set shift is required (Monchi et al, 2001; Nagahama et al, 2001), whereas right DLPFC activation was more involved in monitoring the feedback of the subject's previous response (Lie et al, 2006; Monchi et al, 2001; Nagahama et al, 2001). It has also been proposed that the left DLPFC is a key structure for the implementation of top-down cognitive 
control, based on its consistent activation during color naming in the Stroop task (MacDonald et al, 2000) and when difficult planning is required during the TOL task (Owen et al, 1996).

Functional magnetic resonance imaging studies support the notion that the caudate nucleus also has a key role in executive functions, in particular, in set shifting (Rogers et al, 2000; Monchi et al, 2001; Cools et al, 2004). Most recent studies have shown that the caudate is involved in active planning of a novel action (Monchi et al, 2006a,b) and in cognitive manipulation (Lewis et al, 2004). In particular, Monchi et al (2001) (Figure 4) showed specific involvement of different prefrontal-striatal networks during different stages of WCST performance. The mid-DLPFC (area 9/46) increased activity while subjects received either positive or negative feedback, that is, at the point when the current information must be related to earlier events stored in working memory and, thus, increase the requirements for monitoring, which is known to be the major function of this part of the frontal cortex (see Petrides, 2005). In monkeys, lesions confined to the mid-dorsolateral prefrontal cortical region that covers areas 46,9 , and $9 / 46$, impair severely the monitoring of stimuli or events within working memory, but not the maintenance of information per se (Petrides, $1991,1995,2000)$. The involvement of the mid-DLPFC in the monitoring (tracking) of information in humans has been supported by numerous functional neuroimaging studies across many sensory modalities including language (see Petrides, 2005 for a review). By contrast, a frontal-basal ganglia loop involving the mid-VLPFC (area 47/12), caudate nucleus, and mediodorsal thalamus increased activity, specifically when receiving negative feedback, which signals the need for a mental shift to a new response set. The posterior PFC response, in contrast, was less specific: its increase in activity occurred both during receiving feedback and the response period, indicating a role in the association of specific actions to stimuli. The putamen exhibited greater activity while making a matching response after negative feedback, but not while matching after positive feedback, implying greater involvement during novel than routine actions. Although these event-related fMRI studies with the WCST in young healthy adults (Monchi et al, 2001) confirmed a significant activation of the caudate nucleus, specifically when subjects received negative feedback (that is, when a set-shift was required), there was still no evidence of whether the caudate nucleus was most important for the execution of the shift per se or rather for its planning (that is, the cognitive decision to shift). In a study, using a new card-sorting task called the Montreal Card Sorting Task (MCST), Monchi et al (2006b) were able to dissociate these two aspects of set shifting. Using fMRI, in young healthy adults, they tested the hypothesis that the caudate nucleus was primarily involved in the preparation of a novel action and not in the execution of set shifting per se. In this mixeddesign protocol, they were able to document increased activity in the caudate nucleus and putamen only in conditions in which cognitive planning was required to perform a set shift, whereas significant activation was seen in the subthalamic nucleus in all shifting conditions whether or not planning was required. These observations suggested that the caudate nucleus and putamen were particularly important, respectively, in the planning and motor initiation of a self-generated novel action, whereas the subthalamic nucleus may be required when a new motor
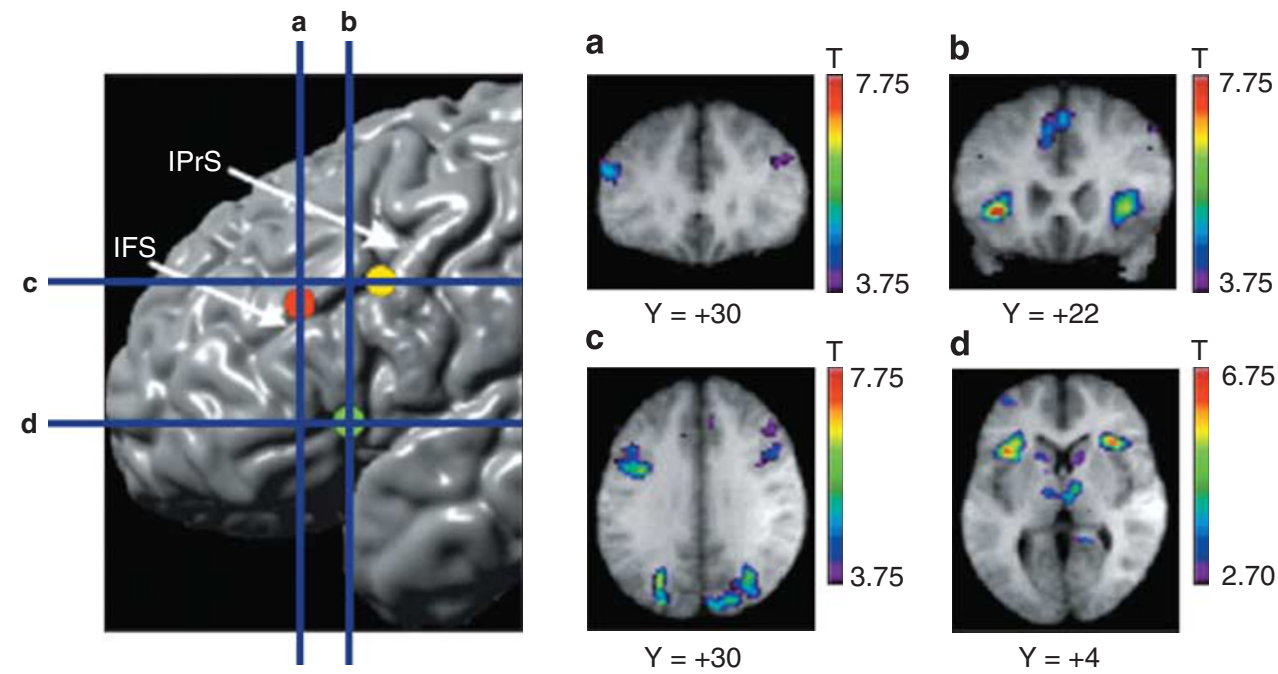

Figure 4. The top left panel displays the sites of the main prefrontal areas identified in the fMRI experiment during Wisconsin Card Sorting Task on a cortical surface rendering an MRI in standard stereotaxic space. The vertical blue lines indicate the anteroposterior level of the coronal sections in (a) and (b). The horizontal blue lines indicate the dorsoventral level of the sections displayed in (c) and (d). The focus in the mid-DLPFC is indicated by the red circle, in mid-VLPFC by the green circle, and in posterior PFC by the yellow circle. (a) Coronal section through the mid-DLPFC peak at $Y=+30 \mathrm{~mm}$. (b) Coronal section through the mid-VPFC peak at $Y=+22 \mathrm{~mm}$. (c) Horizontal section through the posterior PFC peak at $z=+30 \mathrm{~mm}$. (d) Horizontal section through the mid-VLPFC peak at $z=+4 \mathrm{~mm}$. Note also caudate and thalamus activation. All activation peaks shown here occurred during receiving negative feedback minus control feedback. IFS, inferior frontal sulcus; IPrS, inferior precentral sulcus. (Adapted and reproduced with permission from Monchi et al, 2001). 
program was solicited independently of the choice of strategy.

\section{PET Studies}

Position emission tomography has also been used to investigate the neural basis of executive functions. Dagher et al (1999), for example, investigating complex planning with the TOL have described increases in activity in several cortical areas, including the lateral PFC, the lateral premotor areas, anterior cingulate, and caudate nucleus. Although activation studies have a task-specific temporal and spatial resolution, they do not allow determining the underlying neurochemical processes of a given task. To tackle this aspect, the use of PET with specific receptorbinding radioligands has been very promising. Particular attention has been placed on dopaminergic modulation, as it can alleviate or worsen performance on working memory tasks (Fournet et al, 2000; Kimberg et al, 1997; Kimberg and
D’Esposito, 2003; Kulisevsky et al, 1996; Mehta et al, 1999, 2001).

Changes in $\left[{ }^{11} \mathrm{C}\right]$ raclopride-binding potential (BP) provide a reasonable estimate of synaptic dopamine (DA) release in the striatum (Farde et al, 1986). This method has been widely used for investigation of the striatal dopaminergic transmission during various cognitive tasks (Goerendt et al, 2003; Ko et al, 2008a; Monchi et al, 2006a; Ouchi et al, 2002; Zald et al, 2004). To investigate the contribution of striatal DA during set shifting, Monchi et al (2006a) tested young healthy subjects using PET during retrieval with and without shift on a variant of the WCST, the MCST. In this card sorting task, the subject had to match a test card to one of four reference cards by comparing the test card to a previously shown cue card held in memory to find the classification rule. Using D2-DA receptor ligand $\left[{ }^{11} \mathrm{C}\right]$ raclopride, which has a $\mathrm{BP}$ known to be inversely proportional to the concentration of extracellular DA (Endres et al, 1997; Laruelle et al, 2000), Monchi et al
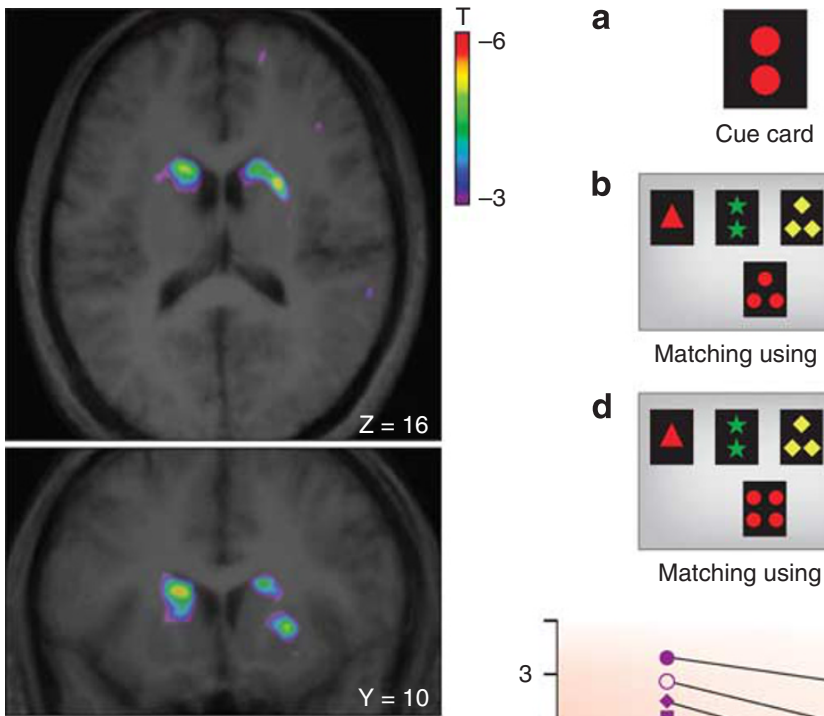

b

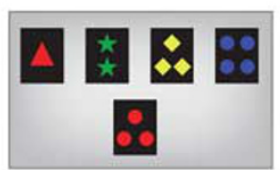

Matching using color

d
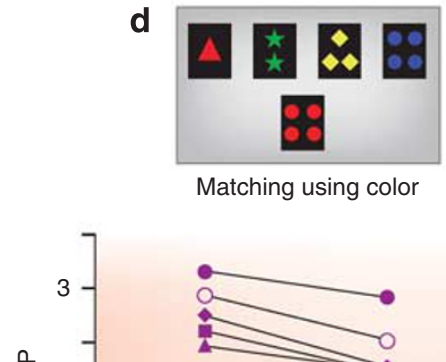

0
0
0
$\nwarrow$
$\square$
0
$=$

-

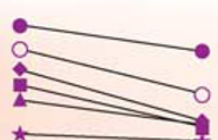

Retrieval Retrieval

without shift

Retrieval
with shift

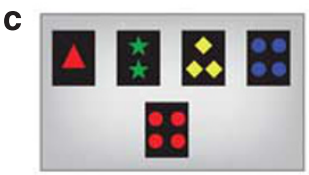

Matching using color

e

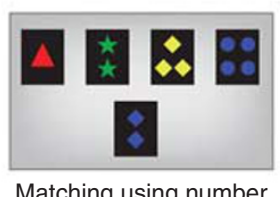

Matching using number

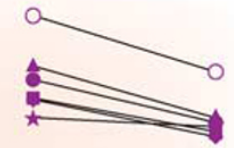

Retrieval

without shift

Retrieva

with shift

Figure 5. Axial $(Z=16)$ and coronal $(Y=10)$ sections of the statistical parametric map of the change in $\left[{ }^{11} \mathrm{C}\right]$ raclopride $\mathrm{BP}$ overlaid on the average $\mathrm{MRI}$ of all subjects in stereotaxic space. The figure displays the significant areas of striatal dopamine release (that is, reduction in $\left.\left[{ }^{11} \mathrm{C}\right] \mathrm{raclopride} \mathrm{BP}\right)$ during the retrieval with shift condition compared with retrieval without shift condition (control) of Montreal Card Sorting Task: (a) left caudate: $t=4.1$; cluster size: 83 voxels, $670 \mathrm{~mm}^{3}$, (b) right caudate: $t=4.1$; cluster size: 42 voxels, $336 \mathrm{~mm}^{3}$, (c) right putamen: $t=4.3$; cluster size: 94 voxels, $752 \mathrm{~mm}$. (Adapted and reproduced with permission from Monchi et al, 2006a). On the bottom right, individual $\left[{ }^{11} \mathrm{C}\right]$ raclopride binding potentials for each subject during retrieval with shift condition and retrieval without shift condition (control), from the left caudate $(p=0.03)$ and right putamen $(p=0.01)$, extracted from a spherical region of interest (radius $5 \mathrm{~mm}$ ) centered at the $x, y$, and $z$ coordinates of the statistical peak revealed by the parametric map. On the top right, the Montreal Card Sorting Task. (a) An example of the cue card that appears for $3.5 \mathrm{~s}$ at the beginning of a block of retrieval trials. In this example, the cue card contains two red circles. The cue card changes for each block. (b, c) An example of two consecutive trials in the retrieval without shift condition. In (b), as the color red is the only attribute shared by the test card and the cue, matching must be based on color. In the following trial (c) the test card is red and the matching is performed according to the same rule. (d, e) An example of two consecutive retrieval trials with shift condition. (d) The test card contains four red stars and hence shares the color attribute with the cue card (containing two red circles, shown in (a). (e) On the subsequent trial, the test card shares a different attribute with the cue card (in this example 'number'). 

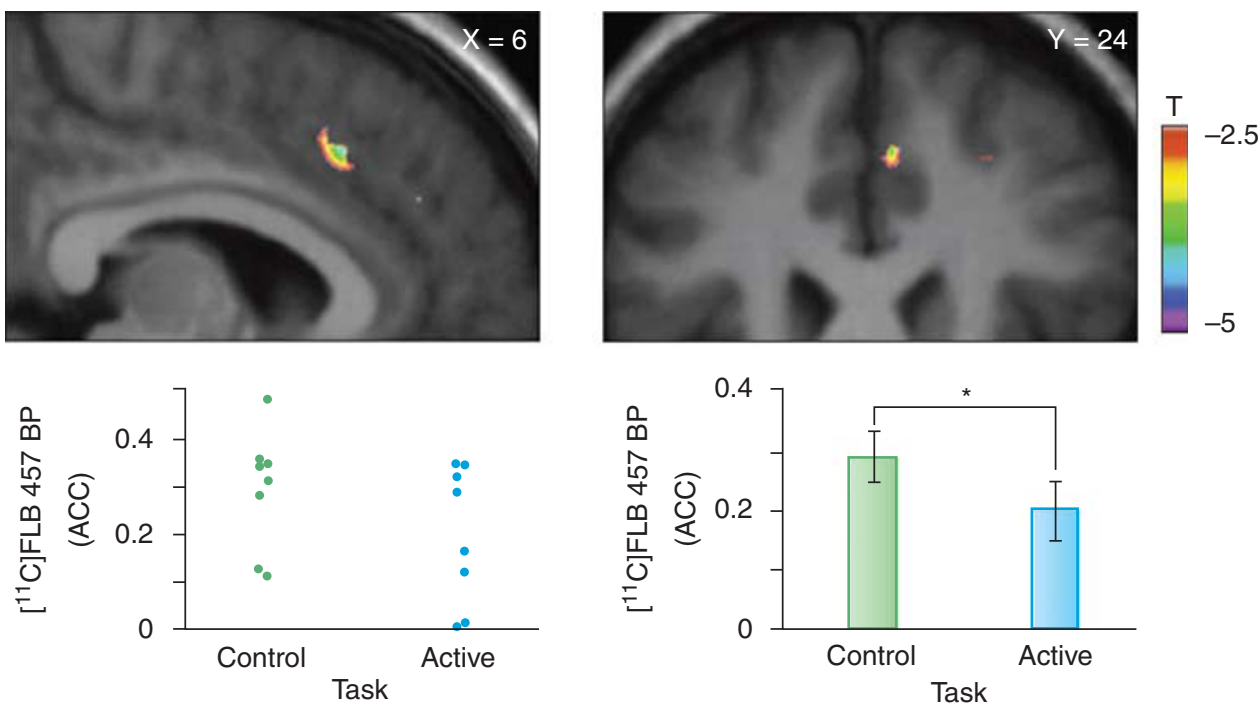

Figure 6. Sagittal $(X=6)$ and coronal $(Y=24)$ section of the statistical parametric map of the change in $\left[{ }^{11} \mathrm{C}\right] \mathrm{FLB} 457 \mathrm{BP}$ overlaid on the average MRI of all subjects in standardized stereotaxic space. The figure displays the significant area of dopamine changes (that is, reduction in [ $\left.{ }^{11} \mathrm{C}\right] \mathrm{FLB} 457 \mathrm{BP}$ ) during active task performance of the Montreal Card Sorting Task compared with the control task at the level of dorsal ACC. (Adapted and reproduced with permission from Ko et al (2009)). On the bottom, individual ACC- $\left[{ }^{11} \mathrm{C}\right] \mathrm{FLB} 457 \mathrm{BP}$ and mean \pm SE of ACC- $\left[{ }^{11} \mathrm{C}\right] \mathrm{FLB} 457 \mathrm{BP}$ during control and active task extracted from a spherical region of interest $(r=3 \mathrm{~mm})$ centered at the $x, y$, and $z$ coordinates of the statistical peak $(X=6, Y=26, Z=40)$ revealed by the parametric map (paired $t$-test, $t(7)=3.85,{ }^{*} p=0.006$ ).

(2006a) revealed striatal reduction in $\left[{ }^{11} \mathrm{C}\right]$ raclopride $\mathrm{BP}$ during planning of a set shift (Figure 5). These findings suggest that striatal DA neurotransmission increases significantly during the performance of specific executive processes. Although $\left[{ }^{11} \mathrm{C}\right]$ raclopride may offer important insights in striatal DA neurotransmission during executive functions (Ko et al, 2008a; Monchi et al, 2006a), its low affinity limits its application to extrastriatal regions such as the PFC (Goldman-Rakic et al, 2000).

In fact, it has been shown that cortical DA has a critical role in executive functions and high-level cognition (Murphy et al, 1996; Watanabe et al, 1997). For instance, during the performance of working memory tasks, DA release increases in the PFC (Aalto et al, 2005a; Sawamoto et al, 2008), and anterior cingulate cortex (ACC) DA receptor density has been shown to be significantly correlated with performance level on the WCST in normal control subjects (Lumme et al, 2007). Recently, Ko et al (2009) (Figure 6) addressed the role of prefrontal DA during set-shifting tasks in healthy subjects by using $\left[{ }^{11} \mathrm{C}\right]$ FLB 457 , a chemical compound with a greater affinity $(K d=20 \mathrm{nM})$ for D2 receptors, which allows evaluation of extrastriatal DA release (Aalto et al, 2005a; Olsson et al, 1999; Sudo et al, 2001). Olsson et al (2004) had previously shown that $\left[{ }^{11} \mathrm{C}\right]$ FLB 457 BP calculated by simplified reference tissue model (Gunn et al, 1997; Lammertsma and Hume, 1996; Sudo et al, 2001) may provide a reasonable estimate of receptor densities in different extrastriatal areas (for example, in cingulate cortex, frontal cortex, thalamus, and temporal cortex), consistent with postmortem studies using $\left[{ }^{125} \mathrm{I}\right]$ epidepride (Kessler et al, 1993). Similarly, $\left[{ }^{11} \mathrm{C}\right] \mathrm{FLB}$ 457 has been shown to be sensitive in detecting changes in extrastriatal endogenous DA concentration in non-human primates (Chou et al, 2000) and in humans (Aalto et al, 2005a, b; Hagelberg et al, 2004; Montgomery et al, 2007). Recently, a study has compared the ability of $\left[{ }^{11} \mathrm{C}\right]$ FLB 457 with another high-affinity DA D2 radioligand, $\left[{ }^{11} \mathrm{C}\right]$ Fallypride, to measure amphetamine-induced changes in DA transmission in the human cortex. Under controlled conditions, $\left[{ }^{11} \mathrm{C}\right] \mathrm{FLB} 457 \mathrm{BP}$ was $30-70 \%$ higher compared with $\left[{ }^{11} \mathrm{C}\right]$ Fallypride $\mathrm{BP}$ in cortical regions. Amphetamineinduced DA release led to a significant decrease of $\left[{ }^{11} \mathrm{C}\right] \mathrm{FLB}$ $457 \mathrm{BP}$ in five out of eight cortical regions evaluated. In contrast, no significant decrease in $\left[{ }^{11} \mathrm{C}\right]$ Fallypride $\mathrm{BP}$ was detected in cortex after amphetamine administration. It was concluded that the difference between these two ligands in detecting changes in the cortical D2 receptor availability after amphetamine administration is related to the higher signal to noise ratio provided by $\left[{ }^{11} \mathrm{C}\right] \mathrm{FLB}$ 457. These findings suggest that $\left[{ }^{11} \mathrm{C}\right]$ FLB 457 is superior to $\left[{ }^{11} \mathrm{C}\right]$ Fallypride for measurement of changes in cortical synaptic DA (Narendran et al, 2009). A similar observation has been made with the use of $\left[{ }^{18} \mathrm{~F}\right]$ Fallypride, which may be useful for measuring amphetamine-induced DA release, but may be unreliable for estimating tonic DA levels in striatum and extrastriatal regions (Cropley et al, 2008).

On the basis of these premises, and previous anatomical and functional imaging studies on card sorting tasks (Buchsbaum et al, 2005; Konishi et al, 2002; Koski and Paus, 2000; Lie et al, 2006; Monchi et al, 2001, 2007), in their study, Ko et al (2009) hypothesized that performance of the MCST may be associated with increases in DA release (decrease BP of $\left.\left[{ }^{11} \mathrm{C}\right] \mathrm{FLB} 457\right)$ in different prefrontal areas, such as the DLPFC (areas 46 and 9/46) and ACC (areas 
32/24). Ko et al (2009) found that extrastriatal DA can influence the performance on a working memory task in healthy subjects with a reduction in $\left[{ }^{11} \mathrm{C}\right] \mathrm{FLB} 457 \mathrm{BP}$ in the right dorsal ACC during the active component of the task (Figure 6). They concluded that neurotransmission may increase in the right dorsal ACC during certain executive processes.

\section{Transcranial Magnetic Stimulation}

Even though functional neuroimaging studies have provided insights into the role of PFC and striatum during set-shifting tasks, neuroimaging alone suffers from the limitation that it provides only neuronal correlates of cognitive performance and often cannot determine a causal relation between the observed brain activity and cognitive performance (Johnson et al, 2007; Rushworth et al, 2002). In other words, the functional imaging studies alone cannot determine whether the engagement of the activated area is essential or just epiphenomenal (Walsh and Cowey, 2000). TMS has been widely used for non-invasive brain stimulation to examine motor, perceptual, and cognitive processes (Hallett, 2007; Pascual-Leone et al, 1998; Walsh and Cowey, 2000). Repetitive TMS (rTMS) has been shown to produce profound and long-lasting effects on neuronal excitability. Combining functional imaging techniques with rTMS provides a valuable probe to study functional connectivity of the human brain (Strafella and Paus, 2000; Strafella et al, 2001, 2003), and can, under certain conditions, be used as a tool to create a 'virtual lesion' and to assess its effects on cognitive behavior (Pascual-Leone et al, 2000; Ko et al, $2008 \mathrm{a}, \mathrm{b})$. The application of rTMS over a cortical area that, at a particular point in time, is actively involved in processing task-relevant information should result in a decline in performance (Enomoto et al, 2001; Huang et al, 2005; Pascual-Leone and Hallett, 1994). Several studies with short-train high-frequency rTMS showed that the stimulation may transiently disrupt the cognitive processes of the targeted area. For example, it has also been shown that $25 \mathrm{~Hz}$ rTMS over the DLPFC during the decision phase of a spatial working memory task selectively interfered with task performance, whereas no effect was seen when the stimulation was delivered over the posterior parietal cortex or the premotor cortex (Koch et al, 2005). rTMS has also been applied offline to pre-treat a given cortical area to create a 'virtual lesion' that outlasts the duration of the stimulation (Walsh and Cowey, 2000), providing considerable advantages as compared with online stimulation (Robertson et al, 2003). Offline high-frequency rTMS over the left DLPFC has been shown to disrupt performance on the Stroop task (Vanderhasselt et al, 2006b), task-set switching (Vanderhasselt et al, 2006a), and divided attention tasks (Wagner et al, 2006).

Recently, Ko et al (2008b) applied rTMS (stimulation train consisted of five pulses of $20 \mathrm{~Hz}$ rTMS; the stimulation intensity was set to $110 \%$ of resting motor threshold of FDI and the total stimulation time was $36 \mathrm{~min}$ ) to the midDLPFC region to test the hypothesis that such stimulation affects monitoring of information in working memory without interfering with other executive functions. They applied rTMS to the right DLPFC and the vertex (control site) at different time points of the WCST. When rTMS was applied to the DLPFC during the period when subjects were receiving feedback regarding their previous response, WCST performance deteriorated, whereas rTMS did not affect performance during matching, either when maintaining set or during set shifting. This selective impairment of the DLPFC is consistent with its proposed role in monitoring of events in working memory.

A recently developed rTMS approach, theta burst stimulation (TBS), has been shown to have longer lasting after effects with a shorter duration and a lower intensity of stimulation than the conventional rTMS (Huang et al, 2005). In particular, continuous TBS (cTBS) has been shown to have a similar but longer effect to that of slow rTMS (that is, inhibitory) when applied to the motor cortex $-20 \mathrm{~s}$ of stimulation may result in a lasting effect of up to $20 \mathrm{~min}$, and $40 \mathrm{~s}$ of stimulation up to $60 \mathrm{~min}$. This long-lasting inhibitory effect of cTBS has been replicated by several groups over the primary motor area (Huang et al, 2007a), the premotor area (Koch et al, 2007; Mochizuki et al, 2005), the primary sensory area (Schabrun et al, 2008), the primary visual areas (Franca et al, 2006), the frontal eye field (Hubl et al, 2008), and the DLPFC (Vallesi et al, 2007). Furthermore, cTBS inhibits the BOLD fMRI signal for over $30 \mathrm{~min}$ when applied to the frontal eye field (Hubl et al, 2008). It has been reported that the cTBS effect is NMDAdependent (Huang et al, 2007a) and may increase the GABA levels in the targeted area (Stagg et al, 2009). Owing to its potent inhibitory effects, cTBS is suitable to study TMSinduced effects on cognitive behavior. To investigate the contribution of the DLPFC during set shifting in the MCST and its effect on the striatal dopaminergic system, Ko et al (2008a) applied cTBS to left and right DLPFC (Figure 7). Three cTBS blocks (20 s each) were applied to the left and right DLPFC, and to the vertex before the MCST. Each block was separated by a 1-min interval. Each cTBS block consisted of $5 \mathrm{~Hz}$ of theta burst administered continuously. Each burst consisted of three pulses in $50 \mathrm{~Hz}$ (Huang et al, 2005). Therefore, $60 \mathrm{~s}$ of cTBS (900 pulses) were administered in total on each session.

The aim of the study by Ko et al (2008a) was to transiently disrupt the function of DLPFC and to measure MCST performance and striatal DA release during $\left[{ }^{11} \mathrm{C}\right]$ raclopride PET. A significant hemispheric asymmetry was observed. cTBS of the left DLPFC impaired MCST performance and DA release in the ipsilateral caudate, anterior putamen, and contralateral caudate nucleus as compared with cTBS of the vertex (control). These effects seemed to be limited only to left DLPFC stimulation, whereas right DLPFC stimulation did not influence task performance and $\left[{ }^{11} \mathrm{C}\right]$ raclopride $\mathrm{BP}$ in the striatum (Figure 7). This was the first study showing 
a

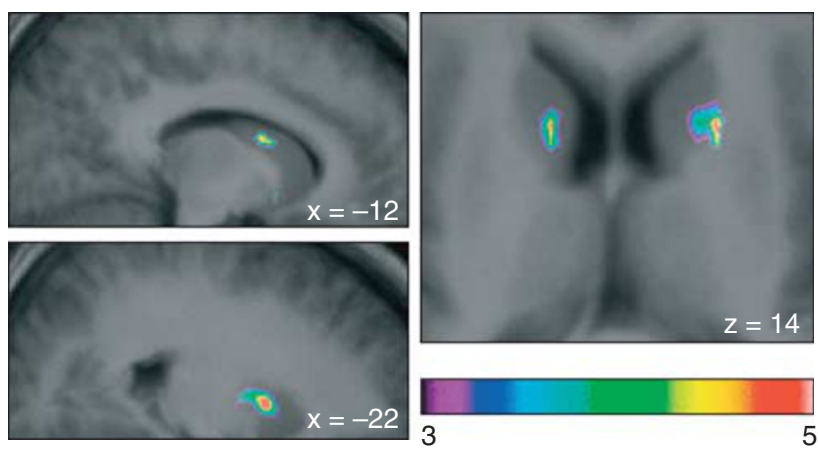

b

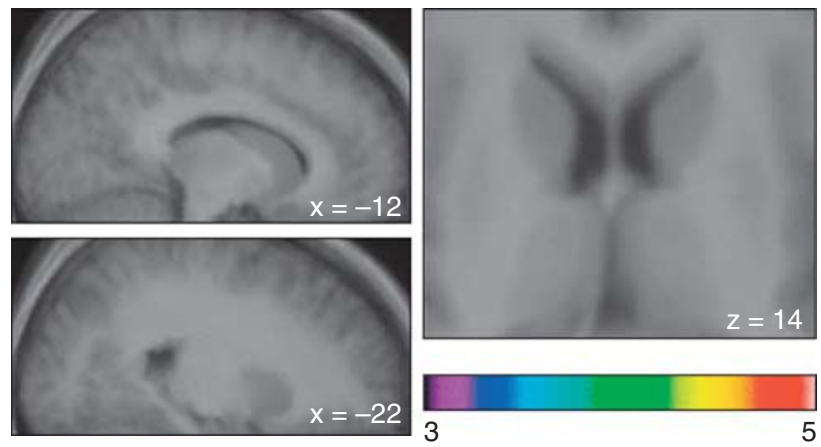

Figure 7. Comparison between left DLPFC and vertex stimulation: (a) Comparison between left DLPFC and vertex stimulation (control condition). Sagittal $(x=-12$ and $x=-22)$ and axial $(z=14)$ sections of the statistical parametric map of the change in $\left[{ }^{11}\right.$ C]raclopride BP overlaid on the average $\mathrm{MRI}$ of all subjects in stereotaxic space. The figure displays the significant areas of striatal dopamine changes during Montreal Card Sorting Task performance after left DLPFC stimulation compared with vertex stimulation (control). (b) Comparison between right DLPFC and vertex stimulation showing the lack of changes in $\left[{ }^{11} \mathrm{C}\right]$ raclopride BP. (Adapted and reproduced with permission from Ko et al, 2008a).

that cTBS, by disrupting left prefrontal function, may indirectly affect striatal DA neurotransmission during performance of executive tasks. This cTBS-induced regional prefrontal effect and modulation of the frontostriatal network may be important for understanding the contribution of hemisphere laterality and its neural bases with regard to executive functions as well as for revealing the neurochemical substrate underlying cognitive deficits.

\section{EXECUTIVE DYSFUNCTION IN PD}

Parkinson's disease is a progressive neurodegenerative disorder, traditionally associated with motor symptoms such as bradykinesia, rigidity, and resting tremor (Strafella et al, 2007, 2008). However, neuropsychological studies have also revealed deficits across a range of cognitive functions even at the early stages of the disease (Dubois and Pillon, 1997; Taylor et al, 1986; Taylor and Saint-Cyr, 1995). Indeed, approximately $15-20 \%$ of the patients tend to develop severe cognitive impairments, and the risk of developing dementia is two to three times higher in PD patients than in aged-matched controls (Aarsland et al, 1996). The non-motor cognitive and behavioral disabilities include deficits of executive function, language, visuospatial/visuoconstructive abilities, memory, attention, skill learning, as well as behavioral changes such as depression, apathy, and impulse control disorders (Taylor and SaintCyr, 1995; Zgaljardic et al, 2004; Monchi et al, 2004; Owen, 2004; Monchi, 2007; Steeves et al, 2009). Although Roberts et al (1994) have shown that prefrontal DA depletion may cause marked working memory deficits in monkeys, cognitive disabilities in PD have also been associated with DA depletion within the caudate nucleus (Lewis et al, 2003; Carbon et al, 2004; Grahn et al, 2008). Several studies have documented that in PD, DA depletion is restricted in the earlier stages to the putamen and the dorsal caudate nucleus, and only later progresses to the more ventral parts of the striatum and the mesocorticolimbic dopaminergic system (Kish et al, 1988; Rosvold, 1972;. Swainson et al, 2000; Cools et al, 2001). Thus, the evolving pattern of cognitive impairments observed in these patients may be best explained in terms of the spatiotemporal progression of DA depletion within the striatum and the terminal distribution of its cortical afferents. This is highlighted by postmortem neurochemical analysis, which showed uneven patterns of striatal DA loss in patients with PD (Kish et al, 1988). The study revealed that the putamen is more severely depleted than the caudate nucleus, and that the caudal putamen is more affected than its rostral area. Within the caudate nucleus, DA depletion was greatest in the rostrodorsal extent of the head of the nucleus, an area heavily connected with dorsolateral regions of the frontal lobe (Yeterian and Pandya, 1991). By contrast, ventral regions of the caudate, which are preferentially connected with more ventral regions of the frontal lobe (including the ventrolateral PFC) (Yeterian and Pandya, 1991), are relatively spared in early $\mathrm{PD}$. This uneven dopaminergic loss explains why dopaminergic therapy, while improving motor symptoms, may not necessarily have the same effects on various cognitive functions (Swainson et al, 2000; Cools et al, 2001). In fact, there is evidence that cognitive disabilities improve differently to dopaminergic replacement therapy depending on the neural pathways underlying the cognitive function being tested (Gotham et al, 1988). Cognitive tasks, such as probabilistic reversal learning, that challenge the ventral frontostriatal circuit, which is relatively spared from DA depletion (at least in early stages) in $\mathrm{PD}$, reveal decreased performance with dopaminergic treatment (Cools et al, 2001). In contrast, PD patients showed improved cognitive abilities after DA therapy on tests that engaged the dorsal frontostriatal circuit (that is, DLPFC, posterior parietal cortex, and dorsal caudate) associated with a severe DA depletion (Cools et al, 2001). According to the 'dopamine overdose model', in the parkinsonian brain, DA replacement therapy normalizes 
DA levels in severely depleted areas, such as the dorsal striatum and its connections to the DLPFC, while detrimentally 'overdosing' the relatively intact ventral striatum and its connections to the VLPFC.

Several neuroimaging studies in PD patients have documented the involvement of the frontostriatal networks in executive dysfunctions, in particular, in engaging the a

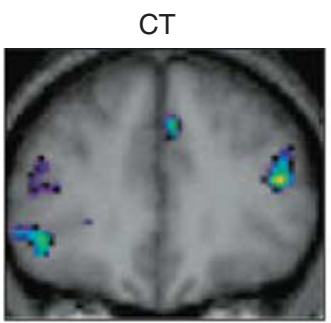

$y=+32$

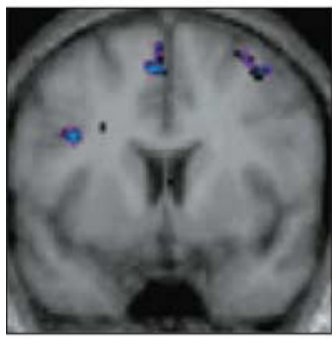

$y=+6$

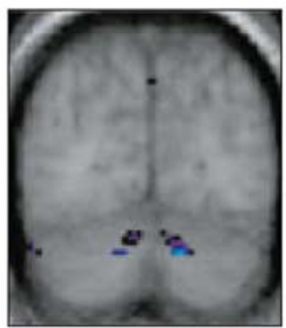

$y=-76$
PD

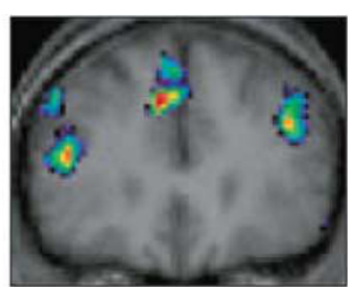

$y=+32$

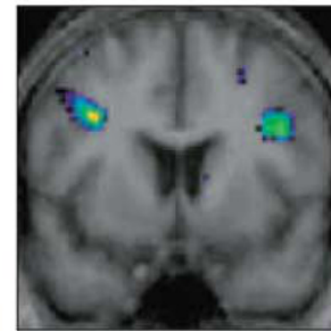

$y=+6$

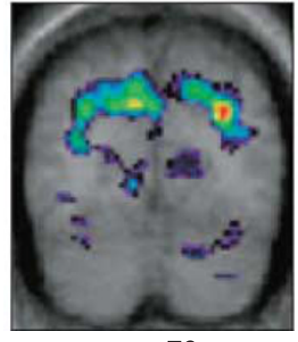

$y=-76$

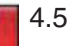

b

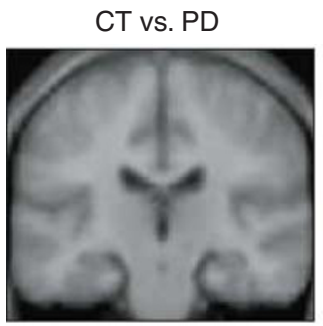

$y=-24$

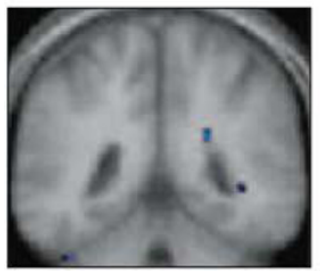

$y=-76$
INTER-GROUP ANALYSIS

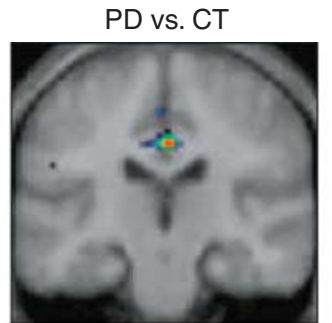

$y=-24$

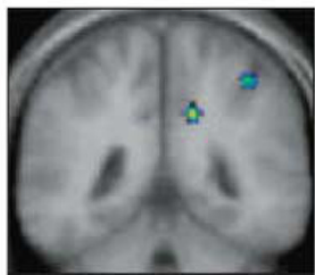

$y=-76$
T
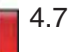

3

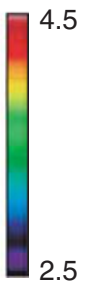

nigrostriatal and mesocortical pathways (Owen et al, 1998; Dagher et al, 2001; Cools et al, 2002; Mattay et al, 2002). Monchi et al (2004), using fMRI, showed in PD patients (with no history of neuropsychiatric problems, including depression) during the performance of the WCST a decreased activation both in the VLPFC (when receiving negative feedback) and the posterior PFC (when matching after negative feedback). In the healthy controls, these prefrontal regions specifically co-activated with the striatum during those stages of task performance. In contrast, greater activation was found in the PD patients in prefrontal regions, such as the posterior and DLPFC, when receiving positive or negative feedback that were not co-activated with the striatum in controls. These findings suggested that both decreased and increased activation can occur in prefrontal areas during cognitive performance, and that the pattern of activity observed in a specific area of the PFC depended on its specific relationship with the striatum for the task at hand. Later, these observation where confirmed in another fMRI study in a similar group of PD patients using a different set-shifting task (that is, MCST) (Monchi et al, 2007) (Figure 8), in which a pattern of cortical activation was characterized by either reduced or increased activation depending on whether the caudate nucleus was involved or not in the task. This activation pattern included not only the prefrontal regions but also posterior cortical areas in the parietal and prestriate cortex. These findings did not agree with the traditional model, which proposes that the nigrostriatal DA depletion results in decreased cortical activity, and provided evidence in favor of the hypothesis that not only the nigrostriatal but also the mesocortical dopaminergic substrate may have a significant role in the cognitive deficits observed in PD. $\mathrm{A} \mathrm{H}_{2}^{15} \mathrm{O}$-PET study in healthy and mildly affected PD patients with no history of neuropsychiatric problems (Dagher et al, 2001), showed no behavioral differences on the TOL test, but nevertheless showed different neuronal activation pattern. In the two groups, overlapping areas of the PFC were activated but, although the right caudate nucleus was activated in the control group, this was not evident in the

Figure 8. Location of peaks within the retrieval with shift vs the retrieval without shift condition of the Montreal Card Sorting Task in PD and healthy controls during fMRI. Coronal sections are shown. The anatomical MRI images shown are the average of $T_{1}$ acquisitions transformed into stereotaxic space for each group in the intra-group analysis and for both groups in the inter-group analysis. (a) Intra-group analysis. The images display significant activation in the left VLPFC and caudate nucleus in the control group, whereas none is observed in the Parkinson's disease group. They also show larger activations in the control group than in the patient group in the posterior cingulate cortex and the posterior parietal cortex bilaterally. (b) Inter-group analysis. Images display significantly greater activity in the control group vs the patient group in the left dorsolateral PFC and orbitofrontal cortex, as well as the right VLPFC, whereas no significantly increased activity is observed in the patient vs control group subtraction. (Adapted and reproduced with permission from Monchi et al, 2007). 
PD patients. This suggested that normal frontal lobe activation can occur in PD despite abnormal processing within the basal ganglia. Moreover, they found that right hippocampus activity was suppressed in the controls and enhanced in the PD patients. This could represent a shift in PD during performance of the TOL task, possibly resulting from insufficient working memory capacity within the frontostriatal system. In another study, Owen et al (1998) examined the effects of striatal DA depletion on cortical and subcortical blood flow changes using the same task (that is, TOL) in patients with moderate PD and age-matched controls. Relative to control conditions, the planning task was associated with an increase in cerebral blood flow in the internal segment of the right globus pallidus in the age-matched control subjects and a decrease in the same region in the patients with $\mathrm{PD}$. They concluded that striatal DA depletion disrupts the normal pattern of basal ganglia outflow in PD and consequently, affects the expression of frontal-lobe functions by interrupting normal transmission of information through frontostriatal circuitry.

To date, there is some interesting imaging evidence that DA replacement therapy may not have the same effect on the identified motor and cognitive frontostriatal networks. In fact, previous FDG-PET studies have shown that, unlike the PD-related motor pattern (PDRP), the PD-related cognitive pattern (PDCP) expression is not significantly altered by antiparkinsonian treatment with either intravenous levodopa or deep brain stimulation (Huang et al, 2007b). In these studies, network analysis in non-demented PD patients with no history of depression identified a spatial covariance pattern associated with cognitive function, and significant correlations between this PDCP expression and performance on tests of memory and executive function. However, antiparkinsonian treatment failed to detect significant changes in PDCP expression, despite concurrent improvement in motor ratings and reductions in abnormal PDRP activity.

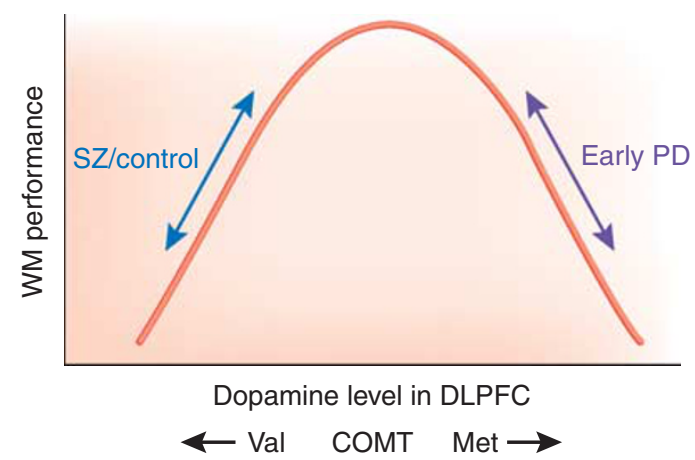

Figure 9. Inverted U-shaped relationship between working memory (WM) performance and dopamine level in the DLPFC. The COMT met/met genotype is expected to confer a higher baseline dopamine level than the $\mathrm{val} / \mathrm{val}$ genotype. This has opposing behavioral consequences in schizophrenics (SZ)/controls and those with early PD, suggesting that their relative positions on the curve differ. (Adapted and reproduced with permission from Williams-Gray et al, 2007).
Recently, it has been proposed that, in PD, the dysfunction in dopaminergic frontostriatal networks may be influenced by a common functional polymorphism ( $\mathrm{val}^{158} \mathrm{met}$ ) within the catechol $O$-methyltransferase (COMT) gene. COMT is an enzyme that regulates DA levels in cortical areas. A polymorphism in COMT, resulting in a substitution of valine for methionine at codon 158 (val ${ }^{158}$ met), may affect PD cognitive performance (Williams-Gray et al, 2008). A low activity COMT genotype (met/met), for example, causes higher DA levels in the PFC, decreases performance on the TOL test, and decreases frontoparietal activity (Williams-Gray et al, 2007) (Figure 9). WilliamsGray et al (2008) compared PD patients with high (val/val) to low (met/met) activity COMT genotypes using an attentional control task. The genotype had a critical impact on task strategy, whereas patients with high-activity COMT genotypes (val/val) adopted a typical approach of preferentially shifting attention, those with low activity genotypes (met/met) failed to adopt such a strategy, suggesting an inability to form an attentional 'set'. Moreover, this behavior was associated with significant underactivation across the frontoparietal attentional network. Furthermore, they showed an interactive effect of COMT genotype and dopaminergic medication on task performance and BOLD response.

Exogenous levodopa caused a larger decrease of prefrontal functions in val/val compared with met/met $\mathrm{PD}$ patients (Williams-Gray et al, 2008). A demonstration of this inverted U-shaped function between DA levels and prefrontal functions can be seen in Figure 9. A similar inverted U-shaped relationship was found by Rowe et al (2008a) between the severity of motor dysfunctions in PD patients and the activity in prefrontal areas and the caudate. They observed that the lateral PFC and caudate nucleus had a non-linear U-shaped relationship between motor disease severity and regional brain activation. Dopaminergic treatment led to a shift in this U-shaped function, supporting the hypothesis of differential neurodegeneration in separate motor and cognitive cortico-striato-thalamocortical circuits. In a separate study (Rowe et al, 2008b), they also investigated whether the $\mathrm{val}^{158}$ met functional polymorphism of COMT influenced age-related changes in gray matter density and volume, both in healthy individuals and PD patients. val/val homozygotes (low prefrontal cortical DA) had more gray matter in early adulthood, but this difference disappeared with increasing age. The insula and ventral PFC had higher gray matter volume in younger, but not older, val/val homozygotes. Conversely, the dominant premotor cortex revealed genotypic differences in gray matter density in later life. There were no global or local interactions between PD and COMT $\mathrm{val}^{158} \mathrm{met}$ genotype on morphometry. As the val ${ }^{158}$ met polymorphism is associated with differences in cortical DA metabolism, these data suggest a role for DA in cortical development followed by differential vulnerability to cortical atrophy across the adult life span. 
It is important to acknowledge that other neurotransmitters may have a role in the cognitive deficits observed in PD (Grahn et al, 2008). For example, noradrenergic, serotoninergic, and cholinergic deafferentations of the cortex also occur in PD (Agid et al, 1987a) and may have a significant role in some of the cognitive deficits observed. Similarly, cortical Lewy bodies, which may occur even in the early stages of $\mathrm{PD}$, may have a contributory role (Byrne et al, 1989; Gibb et al, 1989). Finally, patients with PD have DA depletion within the frontal cortex itself (Scatton et al, 1983) through the degeneration of the mesocortical DA pathway. However, this system is known to be less severely affected than the nigrostriatal DA system in PD (Agid et al, 1987b) and possibly at a later stage of the disease process.

\section{CONCLUSIONS AND FUTURE RESEARCH DIRECTIONS}

We are constantly faced with changing circumstances in which executive processes are regularly called upon when generation and monitoring of appropriate strategies are required, and novel plans of action must be formulated and conducted. As we have observed in the above review, executive functions are not exclusively linked to frontalcortical areas, and involve a complex network of frontalcortical and subcortical circuitries. In fact, lesion studies have shown that executive disabilities do exist in patients with damage to areas other than frontal area. The recent developments in imaging techniques, such as DTI, fMRI, and PET ligand studies, along with non-invasive brain stimulation techniques (that is, TMS) and genetic studies are offering valuable insights into the neuronal networks and molecular mechanisms of executive functions. In addition, the key role played by dopaminergic pathways and their underlying networks make PD an ideal and probably the best available human model of dopaminergic dysfunction. This neurodegenerative condition with the assistance of the rapidly developing cutting-edge imaging technology may be able to provide in vivo valuable insights into the basic molecular mechanisms of executive dysfunction and may aid to disentangle the cortical/subcortical networks and neurobiological underpinnings of executive processes.

\section{ACKNOWLEDGEMENTS}

SEL is supported by a postdoctoral scholarship from FRSQ, APS is supported by CIHR Investigator Award.

\section{DISCLOSURE/CONFLICT OF INTEREST}

The authors declare no conflict of interest.

\section{REFERENCES}

Aalto S, Bruck A, Laine M, Nagren K, Rinne JO (2005a). Frontal and temporal dopamine release during working memory and attention tasks in healthy humans: a positron emission tomography study using the high-affinity dopamine D2 receptor ligand $\left[{ }^{11} \mathrm{C}\right] F L B$ 457. J Neurosci 25: 2471-2477.

Aalto S, Ihalainen J, Hirvonen J, Kajander J, Scheinin H, Tanila H et al (2005b). Cortical glutamate-dopamine interaction and ketamine induced psychotic symptoms in man. Psychopharmacology (Berl) 182: 375-383.

Aarsland D, Tandberg E, Larsen JP, Cummings JL (1996). Frequency of dementia in Parkinson disease. Arch Neurol 53: 538-542.

Agid Y, Javoy-Agid E, Ruberg M (1987a). Biochemistry of neurotransmitters in Parkinson's disease. In: Marsden CD, Fahn S (eds). Movement Disorders. Butterworth: London. pp 166-230.

Agid Y, Ruberg M, Dubois B, Pillon B (1987b). Anatomoclinical and biochemical concepts of subcortical dementia. In: Stahl SM, Iversen SD, Goodman EC (eds). Cognitive Neurochemistry. Oxford University Press: Oxford. pp 248-271.

Alexander GE, Crutcher MD (1990). Functional architecture of basal ganglia circuits: neural substrates of parallel processing. Trends Neurosci 13: 266-271.

Alexander GE, DeLong MR, Strick PL (1986). Parallel organization of functionally segregated circuits linking basal ganglia and cortex. Annu Rev Neurosci 9: 357-381.

Andrés P (2003). Frontal cortex as the central executive of working memory: time to revise our view. Cortex 39: 871-895.

Aron AR, Monsell S, Sahakian BJ, Robbins TW (2004a). A componential analysis of task-switching deficits associated with lesions of left and right frontal cortex. Brain 127(Pt 7): 1561-1573.

Aron AR, Robbins TW, Poldrack RA (2004b). Inhibition and the right inferior frontal cortex. Trends Cogn Sci 8: 170-177.

Baddeley A (1998). The central executive: a concept and some misconceptions. $J$ Int Neuropsychol Soc 4: 523-526.

Baddeley AD (1986). Working Memory. Clarendon Press and Oxford University Press: Oxfordshire and Oxford, New York.

Barbas $H$ (2007). Flow of information for emotions through temporal and orbitofrontal pathways. J Anat 211: 237-249.

Barceló F, Rubia FJ (1998). Non-frontal P3b-like activity evoked by the Wisconsin Card Sorting Test. Neuroreport 9: 747-751.

Barceló F, Sanz M, Molina V, Rubia F (1997). The Wisconsin Card Sorting Test and the assessment of frontal function: a validation study with event-related potentials. Neuropsychologia 35: 399-408.

Bast T (2007). Toward an integrative perspective on hippocampal function: from the rapid encoding of experience to adaptive behavior. Rev Neurosci 18: 253-281.

Bench CJ, Frith CD, Grasby PM, Friston KJ, Paulesu E, Frackowiak RSJ et al (1993). Investigations of the functional anatomy of attention using the Stroop test. Neuropsychologia 31: 907-922.

Berman KF, Ostrem JL, Randolph C, Gold J, Goldberg TE, Coppola R et al (1995). Physiological activation of a cortical network during performance of the Wisconsin Card Sorting Test: a positron emission tomography study. Neuropsychologia 33: 1027-1046.

Buchsbaum BR, Greer S, Chang WL, Berman KF (2005). Meta-analysis of neuroimaging studies of the Wisconsin card-sorting task and component processes. Hum Brain Mapp 25: 35-45.

Burnod Y, Baraduc P, Battaglia-Mayer A, Guigon E, Koechlin E, Ferraina S et al (1999). Parieto-frontal coding of reaching: an integrated framework. Exp Brain Res 129: 325-346

Byrne EJ, Lennox G, Lowe J, Godwin-Austen RB (1989). Diffuse Lewy body disease: clinical features in 15 cases. I Neurol Neurosurg Psychiatry 52: 709-717.

Calzavara R, Mailly P, Haber SN (2007). Relationship between the corticostriatal terminals from areas 9 and 46, and those from area $8 \mathrm{~A}$, dorsal and rostral premotor cortex and area 24c: an anatomical substrate for cognition to action. Eur J Neurosci 26: 2005-2024.

Carbon M, Ma Y, Barnes A, Dhawan V, Chaly T, Ghilardi MF et al (2004). Caudate nucleus: influence of dopaminergic input on sequence learning and brain activation in Parkinsonism. Neuroimage 21: 1497-1507.

Carlesimo GA, Perri R, Turriziani P, Tomaiuolo F, Caltagirone C (2001). Remembering what but not where: independence of spatial and visual working memory in the human brain. Cortex 37: 457-473.

Champod AS, Petrides M (2007). Dissociable roles of the posterior parietal and the prefrontal cortex in manipulation and monitoring processes. Proc Natl Acad Sci USA 104: 14837-14842.

Chou YH, Halldin C, Farde L (2000). Effect of amphetamine on extrastriatal D2 dopamine receptor binding in the primate brain: a PET study. Synapse 38 : 138-143.

Cropley VL, Innis RB, Nathan PJ, Brown AK, Sangare JL, Lerner A et al (2008). Small effect of dopamine release and no effect of dopamine depletion on $\left[{ }^{18} \mathrm{~F}\right]$ fallypride binding in healthy humans. Synapse 62(6): 399-408. 
Collette F, Hogge M, Salmon E, Van der Linden M (2006). Exploration of the neural substrates of executive functioning by functional neuroimaging. Neuroscience 139: 209-221.

Cools R, Barker RA, Sahakian BJ, Robbins TW (2001). Enhanced or impaired cognitive function in Parkinson's disease as a function of dopaminergic medication and task demands. Cereb Cortex 11: 1136-1143. This paper provided evidence of the striatal dopamine 'overdose' hypothesis.

Cools R, Clark L, Robbins TW (2004). Differential responses in human striatum and prefrontal cortex to changes in object and rule relevance. J Neurosci 24: 1120-1135.

Cools R, Stefanova E, Barker RA, Robbins TW, Owen AM (2002). Dopaminergic modulation of high-level cognition in Parkinson's disease: the role of the prefrontal cortex revealed by PET. Brain 125(Pt 3): 584-594.

Dagher A, Owen AM, Boecker H, Brooks DJ (1999). Mapping the network for planning: a correlational PET activation study with the Tower of London task. Brain 122: 1973-1987.

Dagher A, Owen AM, Boecker H, Brooks DJ (2001). The role of the striatum and hippocampus in planning: a PET activation study in Parkinson's disease. Brain 124(Pt 5): 1020-1032.

Dias R, Robbins TW, Roberts AC (1996). Dissociation in prefrontal cortex of affective and attentional shifts. Nature 380: 69-72.

Diwadkar VA, Carpenter PA, Just MA (2000). Collaborative activity between parietal and dorso-lateral prefrontal cortex in dynamic spatial working memory revealed by fMRI. Neuroimage 12: 85-99.

Dubois B, Levy R, Verin M, Teixeira C, Agid Y, Pillon B (1995). Experimental approach to prefrontal functions in humans. Ann N Y Acad Sci 769: 41-60.

Dubois B, Pillon B (1997). Cognitive deficits in Parkinson's disease. J Neuro/ 244: 2-8.

Endres CJ, Kolachana BS, Saunders RC, Su T, Weinberger D, Breier A et al (1997). Kinetic modeling of $\left[{ }^{11} \mathrm{C}\right]$ raclopride: combined PET-microdialysis studies. J Cereb Blood Flow Metab. 17(9): 932-942.

Enomoto H, Ugawa Y, Hanajima R, Yuasa K, Mochizuki H, Terao Y et al (2001). Decreased sensory cortical excitability after $1 \mathrm{~Hz}$ rTMS over the ipsilateral primary motor cortex. Clin Neurophysiol 112: 2154-2158.

Eslinger PJ, Damasio AR (1985). Severe disturbance of higher cognition after bilateral frontal lobe ablation: patient EVR. Neurology 35: 1731-1741.

Farde L, Hall H, Ehrin E, Sedvall G (1986). Quantitative analysis of D2 dopamine receptor binding in the living human brain by PET. Science 231: 258-261.

Fournet N, Moreaud O, Roulin JL, Naegele B, Pellat J (2000). Working memory functioning in medicated Parkinson's disease patients and the effect of withdrawal of dopaminergic medication. Neuropsychology 14: 247-253.

Franca M, Koch G, Mochizuki H, Huang YZ, Rothwell JC (2006). Effects of theta burst stimulation protocols on phosphene threshold. Clin Neurophysiol 117: 1808-1813.

Gibb WR, Luthert PJ, Janota I, Lantos PL (1989). Cortical Lewy body dementia: clinical features and classification. J Neurol Neurosurg Psychiatry 52: 185-192.

Godefroy $O$ (2003). Frontal syndrome and disorders of executive functions. J Neurol 250: $1-6$

Goerendt IK, Messa C, Lawrence AD, Grasby PM, Piccini P, Brooks DJ (2003). Dopamine release during sequential finger movements in health and Parkinson's disease: a PET study. Brain 126: 312-325.

Goldman-Rakic PS (1987). Circuitry of the frontal association cortex and its relevance to dementia. Arch Gerontol Geriatr 6: 299-309.

Goldman-Rakic PS, Muly III EC, Williams GV (2000). D(1) receptors in prefrontal cells and circuits. Brain Res Brain Res Rev 31: 295-301.

Gotham AM, Brown RG, Marsden CD (1988). 'Frontal' cognitive function in patients with Parkinson's disease 'on' and 'off' levodopa. Brain 111(Pt 2): 299-321.

Grabli D, McCairn K, Hirsch EC, Agid Y, Féger J, François C et al (2004). Behavioural disorders induced by external globus pallidus dysfunction in primates: I. Behavioural study. Brain 127: 2039-2054.

Grahn JA, Parkinson JA, Owen AM (2008). The cognitive functions of the caudate nucleus. Prog Neurobiol 86: 141-155. This manuscript emphasizes the important role of the caudate nucleus in different cognitive functions and in relation to $\mathrm{PD}$.

Gunn RN, Lammertsma AA, Hume SP, Cunningham VJ (1997). Parametric imaging of ligand-receptor binding in PET using a simplified reference region model. Neuroimage 6: 279-287.

Haber SN, Kim KS, Mailly P, Calzavara R (2006). Reward-related cortical inputs define a large striatal region in primates that interface with associative cortical connections, providing a substrate for incentive-based learning. J Neurosci 26 8368-8376.

Haber SN, Kunishio K, Mizobuchi M, Lynd-Balta E (1995). The orbital and medial prefrontal circuit through the primate basal ganglia. J Neurosci 15(7 Pt 1): 4851-4867.

Hagelberg N, Aalto S, Kajander J, Oikonen V, Hinkka S, Nagren K et al (2004). Alfentanil increases cortical dopamine D2/D3 receptor binding in healthy subjects. Pain 109: 86-93.
Hallett M (2007). Transcranial magnetic stimulation: a primer. Neuron 55: 187-199. Hariri AR, Bookheimer SY, Mazziotta JC (2000). Modulating emotional responses: effects of a neocortical network on the limbic system. Neuroreport 11: 43-48.

Hariri AR, Mattay VS, Tessitore A, Fera F, Weinberger DR (2003). Neocortical modulation of the amygdala response to fearful stimuli. Biol Psychiatry 53 494-501.

Huang C, Mattis P, Tang C, Perrine K, Carbon M, Eidelberg D (2007b). Metabolic brain networks associated with cognitive function in Parkinson's disease. Neuroimage 34: 714-723.

Huang YZ, Chen RS, Rothwell JC, Wen HY (2007a). The after-effect of human theta burst stimulation is NMDA receptor dependent. Clin Neurophysiol 118: 1028-1032.

Huang YZ, Edwards MJ, Rounis E, Bhatia KP, Rothwell JC (2005). Theta burst stimulation of the human motor cortex. Neuron 45: 201-206. This paper demonstrated for the first time the strong modulatory effect of TBS on the underlying cortex.

Hubl D, Nyffeler T, Wurtz P, Chaves S, Pflugshaupt T, Lüthi M et al (2008). Time course of blood oxygenation level-dependent signal response after theta burst transcranial magnetic stimulation of the frontal eye field. Neuroscience 151 921-928

Johnson JA, Strafella AP, Zatorre RJ (2007). The role of the dorsolateral prefrontal cortex in bimodal divided attention: two transcranial magnetic stimulation studies. J Cogn Neurosci 19: 907-920.

Johnson Jr R, Barnhardt J, Zhu J (2003). The deceptive response: effects of response conflict and strategic monitoring on the late positive component and episodic memory-related brain activity. Biol Psychol 64: 217-253.

Jueptner M, Weiller C (1998). A review of differences between basal ganglia and cerebellar control of movements as revealed by functional imaging studies. Brain 121(Pt 8): 1437-1449.

Kessler RM, Whetsell WO, Ansari MS, Votaw JR, de Paulis T, Clanton JA et al (1993). Identification of extrastriatal dopamine D2 receptors in post mortem human brain with [125I]epidepride. Brain Res 609: 237-243.

Kimberg DY, D'Esposito M (2003). Cognitive effects of the dopamine receptor agonist pergolide. Neuropsychologia 41: 1020-1027.

Kimberg DY, D'Esposito M, Farah MJ (1997). Effects of bromocriptine on human subjects depend on working memory capacity. Neuroreport 8: 3581-3585.

Kish SJ, Shannak K, Hornykiewicz O (1988). Uneven pattern of dopamine loss in the striatum of patients with idiopathic Parkinson's disease. Pathophysiologic and clinical implications. N Engl J Med 318: 876-880.

Ko JH, Monchi O, Ptito A, Bloomfield P, Houle S, Strafella AP (2008a). Theta burst stimulation-induced inhibition of dorsolateral prefrontal cortex reveals hemispheric asymmetry in striatal dopamine release during a set-shifting task: a TMS[(11)C]raclopride PET study. Eur J Neurosci 28: 2147-2155. This manuscript revealed for the first time how TBS-induced modulation of executive performance of the left DLPFC is associated with changes in striatal dopamine release.

Ko JH, Monchi O, Ptito A, Petrides M, Strafella AP (2008b). Repetitive transcranial magnetic stimulation of dorsolateral prefrontal cortex affects performance of the Wisconsin card sorting task during provision of feedback. Int J Biomed Imaging 2008: 143238.

Ko JH, Ptito A, Monchi O, Cho SS, Van Eimeren T, Pellecchia G et al (2009). Increased dopamine release in the right anterior cingulated cortex during the performance of a sorting task: a $\left[{ }^{11} \mathrm{C}\right] \mathrm{FLB} 457$ Pet study. Neuroimage 46: 516521. This manuscript revealed that performance of sorting task is associated with release of dopamine in the specific region of anterior cingulate cortex and DLPFC.

Koch G, Franca M, Mochizuki H, Marconi B, Caltagirone C, Rothwell JC (2007). Interactions between pairs of transcranial magnetic stimuli over the human left dorsal premotor cortex differ from those seen in primary motor cortex. J Physiol 578(Pt 2): 551-562.

Koch G, Oliveri M, Torriero S, Carlesimo GA, Turriziani P, Caltagirone C (2005). rTMS evidence of different delay and decision processes in a fronto-parieta neuronal network activated during spatial working memory. Neuroimage 24 34-39.

Konishi S, Hayashi T, Uchida I, Kikyo H, Takahashi E, Miyashita Y (2002) Hemispheric asymmetry in human lateral prefrontal cortex during cognitive set shifting. Proc Natl Acad Sci USA 99: 7803-7808.

Konishi S, Nakajima K, Uchida I, Sekihara K, Miyashitya Y (1998). No-go dominant brain activity in human inferior prefrontal cortex revealed by functional resonance imaging. Eur J Neurosci 10: 1209-1213.

Koski L, Paus T (2000). Functional connectivity of the anterior cingulate cortex within the human frontal lobe: a brain-mapping meta-analysis. Exp Brain Res 133: 55-65. This manuscript provided important information on the anatomical and functional connections of the ACC with surrounding areas in the prefrontal cortex. 
Kostopoulos P, Petrides M (2003). The mid-ventrolateral prefrontal cortex: insights into its role in memory retrieval. Eur J Neurosci 17: 1489-1497.

Kulisevsky J, Avila A, Barbanoj M, Antonijoan R, Berthier ML, Gironell A (1996). Acute effects of levodopa on neuropsychological performance in stable and fluctuating Parkinson's disease patients at different levodopa plasma levels. Brain 119(Pt 6): 2121-2132.

Lammertsma AA, Hume SP (1996). Simplified reference tissue model for PET receptor studies. Neuroimage 4: 153-158.

Larrue V, Celsis P, Bes A, Marc-Vergens J-P (1994). The functional anatomy of attention in humans: cerebral blood flow changes induced by reading, naming and the Stroop effect. J Cereb Blood Flow Metab 14: 958-962.

Laruelle M (2000). Imaging synaptic neurotransmission with in vivo binding competition techniques: a critical review. J Cereb Blood Flow Metab 20(3): 423-451.

Leh SE, Ptito A, Chakravarty MM, Strafella AP (2007). Fronto-striatal connections in the human brain: a probabilistic diffusion tractography study. Neurosci Lett 419: 113-118. This manuscript reveals the important role of novel imaging techniques such as DTI for studying front-striatal anatomical connections directly in the human brain.

Lehericy S, Ducros M, Krainik A, Francois C, Van de Moortele PF, Ugurbil K et al (2004). 3-D diffusion tensor axonal tracking shows distinct SMA and pre-SMA projections to the human striatum, Cereb Cortex 14(12): 1302-1309.

Levy R, Goldman-Rakic PS (2000). Segregation of working memory functions within the dorsolateral prefrontal cortex. Exp Brain Res 133: 23-32.

Lewis SJ, Cools R, Robbins TW, Dove A, Barker RA, Owen AM (2003). Using executive heterogeneity to explore the nature of working memory deficits in Parkinson's disease. Neuropsychologia 41: 645-654.

Lewis SJ, Dove A, Robbins TW, Barker RA, Owen AM (2004). Striatal contributions to working memory: a functional magnetic resonance imaging study in humans. Eur J Neurosci 19: 755-760.

Lie CH, Specht K, Marshall JC, Fink GR (2006). Using fMRI to decompose the neural processes underlying the Wisconsin Card Sorting Test. Neuroimage 30: 1038-1049.

Lumme V, Aalto S, Ilonen T, Nagren K, Hietala J (2007). Dopamine D2/D3 receptor binding in the anterior cingulate cortex and executive functioning. Psychiatry Res 156: $69-74$.

Luria AR (1971). Memory disturbances in local brain lesions. Neuropsychologia 9: 367-375.

MacDonald III AW, Cohen JD, Stenger VA, Carter CS (2000). Dissociating the role of the dorsolateral prefrontal and anterior cingulate cortex in cognitive control. Science 288: 1835-1838.

Maskati HA, Zbrozyna AW (1989). Stimulation in prefrontal cortex area inhibits cardiovascular and motor components of the defence reaction in rats. $J$ Auton Nerv Syst 28: 117-125.

Matsui H, Nishinaka K, Oda M, Niikawa H, Komatsu K, Kubori T et al (2007). Wisconsin Card Sorting Test in Parkinson's disease: diffusion tensor imaging. Acta Neurol Scand 116: 108-112.

Mattay VS, Tessitore A, Callicott JH, Bertolino A, Goldberg TE, Chase TN et al (2002). Dopaminergic modulation of cortical function in patients with Parkinson's disease. Ann Neurol 51: 156-164.

Mehta MA, Sahakian BJ, McKenna PJ, Robbins TW (1999). Systemic sulpiride in young adult volunteers simulates the profile of cognitive deficits in Parkinson's disease. Psychopharmacology (Berl) 146: 162-174.

Mehta MA, Swainson R, Ogilvie AD, Sahakian J, Robbins TW (2001). Improved short-term spatial memory but impaired reversal learning following the dopamine $\mathrm{D}(2)$ agonist bromocriptine in human volunteers. Psychopharmacology (Berl) 159: 10-20.

Mentzel HJ, Gaser C, Volz H, Rzanny R, Hager F, Sauer H et al (1998). Cognitive stimulation with the Wisconsin Card Sorting Test: functional MR imaging at $1.5 \mathrm{~T}$. Radiology 207: 399-404.

Milner B (1963). Effects of different brain lesions on card sorting: the role of the frontal lobes. Arch Neurol 9: 100-110. The first paper describing the effect of frontal lesions on sorting tasks.

Mochizuki H, Franca M, Huang YZ, Rothwell JC (2005). The role of dorsal premotor area in reaction task: comparing the 'virtual lesion' effect of paired pulse or theta burst transcranial magnetic stimulation. Exp Brain Res 167: 414-421.

Monchi O, Ko JH, Strafella AP (2006a). Striatal dopamine release during performance of executive functions: a $\left[{ }^{11} \mathrm{C}\right]$ raclopride PET study. Neuroimage 33: 907-912. This manuscript revealed how executive task may influence release of dopamine in the striatum.

Monchi O, Petrides M, Doyon J, Postuma RB, Worsley K, Dagher A (2004). Neural bases of set-shifting deficits in Parkinson's disease. J Neurosci 24: 702-710.

Monchi O, Petrides M, Mejia-Constain B, Strafella AP (2007). Cortical activity in Parkinson's disease during executive processing depends on striatal involve- ment. Brain 130(Pt 1): 233-244. This paper describes the significant prefrontalstriatal abnormalities observed in PD while performing an executive task.

Monchi O, Petrides M, Petre V, Worsley K, Dagher A (2001). Wisconsin Card Sorting revisited: distinct neural circuits participating in different stages of the task identified by event-related functional magnetic resonance imaging. J Neurosci 21: 7733-7741.

Monchi O, Petrides M, Strafella AP, Worsley KJ, Doyon J (2006b). Functional role of the basal ganglia in the planning and execution of actions. Ann Neurol 59: 257-264

Montgomery AJ, Asselin MC, Farde L, Grasby PM (2007). Measurement of methylphenidate-induced change in extrastriatal dopamine concentration using [11C]FLB 457 PET. J Cereb Blood Flow Metab 27: 369-377.

Murphy BL, Arnsten AF, Goldman-Rakic PS, Roth RH (1996). Increased dopamine turnover in the prefrontal cortex impairs spatial working memory performance in rats and monkeys. Proc Natl Acad Sci USA 93: 1325-1329. This manuscript revealed how changes in dopamine in the prefrontal cortex may affect working memory tasks.

Nagahama Y, Okada T, Katsumi Y, Hayashi T, Yamauchi H, Oyanagi C et al (2001). Dissociable mechanisms of attentional control within the human prefrontal cortex. Cereb Cortex 11: 85-92.

Nagahama Y, Fukuyama H, Yamauchi Y, Matsuzaki S, Ouchi Y, Kimura J et al (1995). Functional localization and lateralization of the activated cortex during the Wisconsin Card Sorting test. Hum Brain Mapp 2 (abstract).

Nakano K, Kayahara T, Tsutsumi T, Ushiro H (2000). Neural circuits and functional organization of the striatum. J Neurol 247(Suppl. 5): 1-15.

Nambu A, Kaneda K, Tokuno H, Takada M (2002). Organization of corticostriatal motor inputs in monkey putamen. J Neurophysiol 88: 1830-1842.

Narendran R, Frankle WG, Mason NS, Laymon CM, Lopresti BJ, Price JC et al (2009). Positron emission tomography imaging of $D(2 / 3)$ agonist binding in healthy human subjects with the radiotracer $\left[{ }^{11} \mathrm{C}\right]-\mathrm{N}$-propyl-norapomorphine: preliminary evaluation and reproducibility studies. Synapse 63: 574-584.

Nauta WJ (1971). The problem of the frontal lobe: a reinterpretation. J Psychiatr Res 8: $167-187$.

Oliveri M, Turriziani P, Carlesimo GA, Koch G, Tomaiuolo F, Panella M et al (2001). Parieto-frontal interactions in visual-object and visual-spatial working memory: evidence from transcranial magnetic stimulation. Cereb Cortex 11: 606-618.

Olsson H, Halldin C, Farde L (2004). Differentiation of extrastriatal dopamine D2 receptor density and affinity in the human brain using PET. Neuroimage 22: 794-803.

Olsson H, Halldin C, Swahn CG, Farde L (1999). Quantification of $\left[{ }^{11}\right.$ C]FLB 457 binding to extrastriatal dopamine receptors in the human brain. J Cereb Blood Flow Metab 19: 1164-1173.

Ouchi Y, Yoshikawa E, Futatsubashi M, Okada H, Torizuka T, Sakamoto M (2002). Effect of simple motor performance on regional dopamine release in the striatum in Parkinson disease patients and healthy subjects: a positron emission tomography study. J Cereb Blood Flow Metab 22: 746-752.

Owen AM (2004). Cognitive dysfunction in Parkinson's disease: the role of frontostriatal circuitry. Neuroscientist 10: 525-537. This manuscript described the several abnormalities in executive functions that can be observed in PD.

Owen AM, Doyon J, Dagher A, Sadikot A, Evans AC (1998). Abnormal basal ganglia outflow in Parkinson's disease identified with PET. Implications for higher cortical functions. Brain 121(Pt 5): 949-965.

Owen AM, Evans AC, Petrides M (1996). Evidence for a two-stage model of spatial working memory processing within the lateral frontal cortex: a positron emission tomography study. Cereb Cortex 6: 31-38.

Pardo JV, Pardo PJ, Janer KW, Raichle ME (1990). The anterior cingulate cortex mediates processing in the Stroop attentional conflict paradigm. Proc Natl Acad Sci USA 87: 256-259.

Parent A (1990). Extrinsic connections of the basal ganglia. Trends Neurosci 13: 254-258.

Parent A, Hazrati LN (1995). Functional anatomy of the basal ganglia. I. The corticobasal ganglia-thalamo-cortical loop. Brain Res Brain Res Rev 20: 91-127.

Park S, Holzman PS (1993). Association of working memory deficit and eye tracking dysfunction in schizophrenia. Schizophr Res 11: 55-61.

Parnetti L, Calabresi P (2006). Spatial cognition in Parkinson's disease and neurodegenerative dementias. Cogn Process 7(Suppl 5): 77-78.

Pascual-Leone A, Hallett M (1994). Induction of errors in a delayed response task by repetitive transcranial magnetic stimulation of the dorsolateral prefrontal cortex. Neuroreport 5: 2517-2520.

Pascual-Leone A, Tormos JM, Keenan J, Tarazona F, Cañete C, Catalá MD (1998). Study and modulation of human cortical excitability with transcranial magnetic stimulation. J Clin Neurophysiol 15: 333-343.

Pascual-Leone A, Walsh V, Rothwell J (2000). Transcranial magnetic stimulation in cognitive neuroscience-virtual lesion, chronometry, and functional connectivity. 
Curr Opin Neurobiol 10: 232-237. This paper describes the important role of rTMS for studying cognitive functions in-vivo in humans.

Pennartz CM, Groenewegen HJ, Lopes da Silva FH (1994). The nucleus accumbens as a complex of functionally distinct neuronal ensembles: an integration of behavioural, electrophysiological and anatomical data. Prog Neurobiol 42: 719-761.

Petrides M (1991). Monitoring of selections of visual stimuli and the primate frontal cortex. Proc Biol Sci 246: 293-298. This article provided the first demonstration of the role of the mid-DLPFC in monitoring information in working memory.

Petrides M (1995). Impairments on nonspatial self-ordered and externally ordered working memory tasks after lesions of the mid-dorsal part of the lateral frontal cortex in the monkey. J Neurosci 15(1 Pt 1): 359-375. This manuscript provides evidence that lesions of the mid-DLPFC affect a specific aspect of working memory, namely monitoring of the information in working memory.

Petrides M (1996). Fronto-hippocampal interactions in mnemonic processing. In: Kato N (ed). The Hippocampus: Functions and Clinical Relevance. Elsevier: Amsterdam. pp 289-301.

Petrides M (2000). The role of the mid-dorsolateral prefrontal cortex in working memory. Exp Brain Res 133: 44-54.

Petrides M (2002). The mid-ventrolateral prefrontal cortex and active mnemonic retrieval. Neurobiol Learn Mem 78: 528-538.

Petrides M (2005). Lateral prefrontal cortex: architectonic and functional organization. Philos Trans R Soc Lond B Biol Sci 360: 781-795. This manuscript provides a description of the anatomical and functional organization of the lateral prefrontal cortex.

Petrides M (2007). The orbitofrontal cortex: novelty, deviation from expectation, and memory. In: Schoenbaum G, Gottfried JA, Murray EA, Ramus SJ (eds). Linking Affect to Action Ann N Y Acad Sci 1121 33-53.

Petrides M, Pandya DN (1994). Comparative architectonic analysis of the human and the macaque frontal cortex. In: Boller F, Grafman J (eds). Handbook of Neuropsychology. Elsevier: Amsterdam. Vol. 9, pp 17-58. This manuscript provides comparative anatomical information on the human and macaque monkey prefrontal cortex.

Petrides M, Pandya DN (2002). Association pathways of the prefrontal cortex and functional observations. In: Stuss DT, Knight RT (eds). Principles of Frontal Lobe Function. Oxford University Press: New York. Chapter 3, pp 31-50.

Pezawas L, Meyer-Lindenberg A, Drabant EM, Verchinski BA, Munoz KE, Kolachana BS et al (2005). 5-HTTLPR polymorphism impacts human cingulate-amygdala interactions: a genetic susceptibility mechanism for depression. Nat Neurosci 8: 828-834.

Prasad KM, Sahni SD, Rohm BR, Keshavan MS (2005). Dorsolateral prefrontal cortex morphology and short-term outcome in first-episode schizophrenia. Psychiatry Res 140: 147-155.

Ragland JD, Gur RC, Glahn DC, Censits DM, Smith RJ, Lazarev MG et al (1998). Frontotemporal cerebral blood flow change during executive and declarative memory tasks in schizophrenia: a positron emission tomography study. Neuropsychology 12: 399-413.

Rezai K, Andreasen NC, Alliger R, Cohen G, Swayze II V, O'Leary DS (1993). The neuropsychology of the prefrontal cortex. Arch Neurol 50: 636-642.

Rizzuto DS, Mamelak AN, Sutherling WW, Fineman I, Andersen RA (2005). Spatial selectivity in human ventrolateral prefrontal cortex. Nat Neurosci 8 : 415-417.

Roberts AC, De Salvia MA, Wilkinson LS, Collins P, Muir JL, Everitt BJ et al (1994). 6-Hydroxydopamine lesions of the prefrontal cortex in monkeys enhance performance on an analog of the Wisconsin Card Sort Test: possible interactions with subcortical dopamine. J Neurosci 14(5 Pt 1): 2531-2544.

Robertson EM, Théoret H, Pascual-Leone A (2003). Studies in cognition: the problems solved and created by transcranial magnetic stimulation. $J$ Cogn Neurosci 15: 948-960.

Rodriguez-Sanchez JM, Crespo-Facorro B, Iglesias RP, Bosch CG, Alvarez M, Llorca $J$ et al (2005). Prefrontal cognitive functions in stabilized first-episode patients with schizophrenia spectrum disorders: a dissociation between dorsolateral and orbitofrontal functioning. Schizophr Res 77: 279-288.

Rogers RD, Andrews TC, Grasby PM, Brooks DJ, Robbins TW (2000). Contrasting cortical and subcortical activations produced by attentional-set shifting and reversal learning in humans. J Cogn Neurosci 12: 142-162.

Rolls ET (2000). Précis of the brain and emotion. Behav Brain Sci 23: 177-191.

Rosenkranz JA, Grace AA (1999). Modulation of basolateral amygdala neuronal firing and afferent drive by dopamine receptor activation in vivo. J Neurosci 19: 11027-11039.

Rosvold HE (1972). The frontal lobe system: cortical-subcortical interrelationships. Acta Neurobiol Exp (Wars) 32: 439-460.

Rowe JB, Hughes L, Ghosh BCP, Eckstein D, Williams-Gray CH, Fallon S et al (2008a). Parkinson's disease and dopaminergic therapy - differential effects on movement, reward and cognition. Brain 131: 2094-2105.
Rowe JB, Hughes L, Williams-Gray CH, Bishop S, Fallon S, Barker RA et al (2008b). The val(158)met COMT polymorphism's effect on atrophy in healthy aging and Parkinson's disease. Neurobiol Aging [E-pub ahead of print].

Rushworth MF, Hadland KA, Paus T, Sipila PK (2002). Role of the human medial frontal cortex in task switching: a combined fMRI and TMS study. J Neurophysiol 87: 2577-2592.

Sauseng P, Klimesch W, Gruber W, Doppelmayr M, Stadler W, Schabus M (2002). The interplay between theta and alpha oscillations in the human electroencephalogram reflects the transfer of information between memory systems. Neurosci Lett 324: 121-124.

Sawamoto N, Piccini P, Hotton G, Pavese N, Thielemans K, Brooks DJ (2008). Cognitive deficits and striato-frontal dopamine release in Parkinson's disease. Brain 131: 1294-1302.

Scatton B, Javoy-Agid F, Rouquier L, Dubois B, Agid Y (1983). Reduction of cortical dopamine, noradrenaline, serotonin and their metabolites in Parkinson's disease. Brain Res 275: 321-328.

Schabrun SM, Ridding MC, Miles TS (2008). Role of the primary motor and sensory cortex in precision grasping: a transcranial magnetic stimulation study. Eur $\mathrm{J}$ Neurosci 27: 750-756.

Selemon LD, Goldman-Rakic PS (1985). Longitudinal topography and interdigitation of corticostriatal projections in the rhesus monkey. J Neurosci 5: 776-794.

Shallice T (1982). Specific impairments of planning. Philos Trans R Soc Lond B Biol Sci 298: 199-209.

Stagg CJ, Wylezinska M, Matthews PM, Johansen-Berg H, Jezzard P, Rothwell JC et al (2009). Neurochemical effects of theta burst stimulation as assessed by magnetic resonance spectroscopy. J Neurophysiol 101(6): 2872-2877.

Steeves TD, Miyasaki J, Zurowski M, Lang AE, Pellecchia G, Van Eimeren Tet al (2009). Increased striatal dopamine release in Parkinsonian patients with pathological gambling: a $\left[{ }^{11} \mathrm{C}\right]$ raclopride PET study. Brain 132(Pt 5): 1376-1385.

Strafella AP, Paus $T$ (2000). Modulation of cortical excitability during action observation: a transcranial magnetic stimulation study. Neuroreport 11: 2289-2292.

Strafella AP, Paus T, Barrett J, Dagher A (2001). Repetitive transcranial magnetic stimulation of the human prefrontal cortex induces dopamine release in the caudate nucleus. J Neurosci 21: RC157.

Strafella AP, Paus T, Fraraccio M, Dagher A (2003). Striatal dopamine release induced by repetitive transcranial magnetic stimulation of the human motor cortex. Brain 126(Pt 12): 2609-2615.

Strafella AP, Lozano AM, Ballanger B, Poon YY, Lang AE, Moro E (2008). rCBF changes associated with PPN stimulation in a patient with Parkinson's disease: a PET study. Mov Disord 23: 1051-1054.

Strafella AP, Lozano AM, Lang AE, Ko JH, Poon YY, Moro E (2007). Subdural motor cortex stimulation in Parkinson's disease does not modify movement-related rCBF pattern. Mov Disord 22: 2113-2116.

Stuss DT, Alexander MP (2007). Is there a dysexecutive syndrome? Philos Trans $R$ Soc Lond B Biol Sci 362: 901-915.

Sudo Y, Suhara T, Inoue M, Ito H, Suzuki K, Saijo Tet al (2001). Reproducibility of $\left[{ }^{11} \mathrm{C}\right] \mathrm{FLB} 457$ binding in extrastriatal regions. NuCl Med Commun 22: $1215-1221$.

Swainson R, Rogers RD, Sahakian BJ, Summers BA, Polkey CE, Robbins TW (2000). Probabilistic learning and reversal deficits in patients with Parkinson's disease or frontal or temporal lobe lesions: possible adverse effects of dopaminergic medication. Neuropsychologia 38: 596-612.

Takada M, Tokuno H, Nambu A, Inase M (1998). Corticostriatal projections from the somatic motor areas of the frontal cortex in the macaque monkey: segregation versus overlap of input zones from the primary motor cortex, the supplementary motor area, and the premotor cortex. Exp Brain Res 120: 114-128.

Taylor AE, Saint-Cyr JA (1995). The neuropsychology of Parkinson's disease. Brain Cogn 28: 281-296.

Taylor AE, Saint-Cyr JA, Lang AE (1986). Frontal lobe dysfunction in Parkinson's disease. The cortical focus of neostriatal outflow. Brain 109: 845-883.

Tekin S, Cummings JL (2002). Frontal-subcortical neuronal circuits and clinical neuropsychiatry. An update. J Psychosom Res 53: 647-654.

Tulving E, Kapur S, Craik Fl, Moscovitch M, Houle S (1994). Hemispheric encoding/ retrieval asymmetry in episodic memory: positron emission tomography findings. Proc Natl Acad Sci USA 91: 2016-2020.

Vallesi A, Shallice T, Walsh V (2007). Role of the prefrontal cortex in the foreperiod effect: TMS evidence for dual mechanisms in temporal preparation. Cereb Cortex 17: 466-474.

Vanderhasselt MA, De Raedt R, Baeken C, Leyman L, D'haenen H (2006a). The influence of rTMS over the right dorsolateral prefrontal cortex on intentional set switching. Exp Brain Res 172: 561-565.

Vanderhasselt MA, De Raedt R, Baeken C, Leyman L, D'haenen H (2006b). The influence of rTMS over the left dorsolateral prefrontal cortex on Stroop task performance. Exp Brain Res 169: 279-282. 
Wagner M, Rihs TA, Mosimann UP, Fisch HU, Schlaepfer TE (2006). Repetitive transcranial magnetic stimulation of the dorsolateral prefrontal cortex affects divided attention immediately after cessation of stimulation. J Psychiatr Res 40: 315-321.

Walsh V, Cowey A (2000). Transcranial magnetic stimulation and cognitive neuroscience. Nat Rev Neurosci 1: 73-79. This manuscript provides important information on the role of TMS in cognition.

Watanabe M, Kodama T, Hikosaka K (1997). Increase of extracellular dopamine in primate prefrontal cortex during a working memory task. J Neurophysiol 78: 2795-2798.

Williams-Gray CH, Hampshire A, Barker RA, Owen AM (2008). Attentional control in Parkinson's disease is dependent on COMT val 158 met genotype. Brain 131 (Pt 2): 397-408.
Williams-Gray CH, Hampshire A, Robbins TW, Owen AM, Barker RA (2007). Catechol O-methyltransferase Val158Met genotype influences frontoparietal activity during planning in patients with Parkinson's disease. I Neurosci 27: 4832-4838. This paper provides important information on the role of COMT on prefrontal activity.

Yeterian EH, Pandya DN (1991). Prefrontostriatal connections in relation to cortical architectonic organization in rhesus monkeys. J Comp Neurol 312: 43-67.

Zald DH, Boileau I, El-Dearedy W, Gunn R, McGlone F, Dichter GS et al (2004). Dopamine transmission in the human striatum during monetary reward tasks. J Neurosci 24: 4105-4112.

Zgaljardic DJ, Foldi NS, Borod JC (2004). Cognitive and behavioral dysfunction in Parkinson's disease: neurochemical and clinicopathological contributions. J Neural Transm 111: 1287-1301. 